\title{
Controls on phase composition and ice water content in a convection-permitting model simulation of a tropical mesoscale convective system
}

\author{
Charmaine N. Franklin ${ }^{1,2}$, Alain Protat ${ }^{2}$, Delphine Leroy ${ }^{3}$, and Emmanuel Fontaine ${ }^{3}$ \\ ${ }^{1}$ CSIRO, Aspendale, Victoria, Australia \\ ${ }^{2}$ Bureau of Meteorology, Docklands, Victoria, Australia \\ ${ }^{3}$ Laboratoire de Meteorologie Physique, Universite Blaise Pascal, Clermont-Ferrand, France \\ Correspondence to: Charmaine N. Franklin (c.franklin@bom.gov.au) \\ Received: 30 November 2015 - Published in Atmos. Chem. Phys. Discuss.: 19 January 2016 \\ Revised: 15 June 2016 - Accepted: 1 July 2016 - Published: 19 July 2016
}

\begin{abstract}
Simulations of tropical convection from an operational numerical weather prediction model are evaluated with the focus on the model's ability to simulate the observed high ice water contents associated with the outflow of deep convection and to investigate the modelled processes that control the phase composition of tropical convective clouds. The $1 \mathrm{~km}$ horizontal grid length model that uses a singlemoment microphysics scheme simulates the intensification and decay of convective strength across the mesoscale convective system. However, deep convection is produced too early, the OLR (outgoing longwave radiation) is underestimated and the areas with reflectivities $>30 \mathrm{dBZ}$ are overestimated due to too much rain above the freezing level, stronger updraughts and larger particle sizes in the model. The inclusion of a heterogeneous rain-freezing parameterisation and the use of different ice size distributions show better agreement with the observed reflectivity distributions; however, this simulation still produces a broader profile with many high-reflectivity outliers demonstrating the greater occurrence of convective cells in the simulations. Examining the phase composition shows that the amount of liquid and ice in the modelled convective updraughts is controlled by the following: the size of the ice particles, with larger particles growing more efficiently through riming and producing larger IWC (ice water content); the efficiency of the warm rain process, with greater cloud water contents being available to support larger ice growth rates; and exclusion or limitation of graupel growth, with more mass contained in slower falling snow particles resulting in an increase
\end{abstract}

of in-cloud residence times and more efficient removal of LWC (liquid water content). In this simulated case using a $1 \mathrm{~km}$ grid length model, horizontal mass divergence in the mixed-phase regions of convective updraughts is most sensitive to the turbulence formulation. Greater mixing of environmental air into cloudy updraughts in the region of -30 to $0{ }^{\circ} \mathrm{C}$ produces more mass divergence indicative of greater entrainment, which generates a larger stratiform rain area. Above these levels in the purely ice region of the simulated updraughts, the convective updraught buoyancy is controlled by the ice particle sizes, demonstrating the importance of the microphysical processes on the convective dynamics in this simulated case study using a single-moment microphysics scheme. The single-moment microphysics scheme in the model is unable to simulate the observed reduction of mean mass-weighted ice diameter as the ice water content increases. The inability of the model to represent the observed variability of the ice size distribution would be improved with the use of a double-moment microphysics scheme.

\section{Introduction}

Improving the simulation of tropical convective clouds in convection-permitting simulations is an important yet challenging endeavour. Forecasting centres are beginning to use operational numerical weather prediction models with horizontal grid spacing of order of $1 \mathrm{~km}$ and while these models have been shown to improve the diurnal cycle of con- 
vection and the distribution of rain rates (e.g. Clark et al., 2007; Weusthoff et al., 2010), there are numerous deficiencies at these resolutions that impact the accuracy of the forecasts and the confidence in using these models to help guide parameterisation development for coarser-resolution models and develop retrieval algorithms for remotely sensed cloud properties (e.g. Del Genio and Wu, 2010; Shige et al., 2009). One salient aspect of forecasting tropical meteorology is the high ice water contents that are responsible for numerous aircraft safety incidents as discussed by Fridlind et al. (2015). These incidents tend to occur in fully glaciated conditions in the vicinity of deep convection where high ice water contents can cause engine power loss (e.g. Lawson et al., 1998; Mason et al., 2006; Strapp et al., 2015). In recognition of this, an international field campaign called the High Ice Water Content (HIWC) study was conducted out of Darwin in the beginning of 2014 and provided a high-quality database of ice cloud measurements associated with deep tropical convective systems. These observations are a valuable resource for evaluating convection-permitting model simulations and cloud microphysical parameterisations. In this work cloud properties are evaluated from an operational model with the focus on the model's ability to simulate high ice water contents generated from the outflow of deep convection and to understand what modelled processes control the phase composition of the simulated tropical convective clouds.

Many previous convection-permitting modelling studies of tropical convection have documented common biases amongst models including excessive reflectivities above the freezing level, lack of stratiform cloud and precipitation and too much frozen condensate (e.g. Blossey et al., 2007; Lang et al., 2011; Fridlind et al., 2012; Varble et al., 2014a, b). Lang et al. (2011) modified a single-moment microphysics scheme to reduce the biases in simulated radar reflectivities and ice sizes in convective systems and found better success in a weakly organised continental convective case compared to a stronger oceanic MCS (mesoscale convective system). The reason could be due to dynamical errors in the model that had a greater influence on the microphysical characteristics in the simulations of stronger convection. Varble et al. (2014a) compared cloud-resolving and limited-area model simulations with the extensive database of observations from the Tropical Warm Pool - International Cloud Experiment (TWP-ICE). They found excessive vertical velocities even at $100 \mathrm{~m}$ horizontal grid spacings and suggested that the overly intense updraughts are a product of interactions between the convective dynamics and microphysics. These strong updraughts transport condensate and moisture to the upper levels, which contributes to the larger amount of frozen condensate seen in simulations, and the reduced detrainment at lower levels could play a role in the lack of generation of significant stratiform cloud and precipitation. This has been seen by Tao et al. (1993), who showed the importance of the horizontal transport of hydrometeors from the convective to the stratiform regions for the generation of stratiform rainfall.
An increase in stratiform rain was also shown by Ferrier et al. (1996) to occur when the rearward transport of condensate was promoted through more upshear tilted updraughts. Morrison et al. (2009) compared squall line simulations using a single- and double-moment microphysics scheme and determined that the greater stratiform precipitation region produced from the double-moment scheme was due to both a reduced rain evaporation rate in the stratiform region and an increased evaporation rate in the convective region. This had the effect of reducing the intensity of the convection and increasing the mid-level horizontal flux of positively buoyant air from the convective to the stratiform regions. In the operational model used in this study, the microphysics scheme is a single-moment bulk scheme. Model intercomparison studies have shown that double-moment microphysics schemes do not necessarily perform better than single-moment schemes and, in fact, provided that the intercept parameters are not fixed and are able to vary, these more simple schemes can match or even outperform the more complex double-moment schemes in their representation of cloud and rainfall properties (e.g. VanWeverberg et al., 2013; Varble et al., 2014b).

The aims of this study are twofold: firstly to test different configurations of the dynamics, turbulence and microphysical formulations in the model to determine those that best represent tropical convective cloud systems and to understand the sensitivities in the modelled cloud and dynamical properties to these changes; secondly to determine what processes control the phase composition and ice water content in the model. As mentioned previously, observations of HIWC (defined here as $>2 \mathrm{~g} \mathrm{~m}^{-3}$ at $1 \mathrm{~km}$ resolution) typically occur in glaciated conditions. However, as will be shown, the model is unable to replicate this and instead produces mixedphase clouds under the same temperature regimes. For this reason we examine which processes control the modelled phase composition in order to understand how the model produces HIWC. This understanding will aid in improving the representation of these clouds in the model and produce a better forecasting capability. The following section describes the model and observations used in this work. Section 3 compares the simulations with the available observations including a time series comparison with the satellite data, comparison of the simulated radar reflectivity characteristics with those from the Darwin radar and an investigation into the controls on phase composition in the model and how the IWC (ice water content) and ice particle sizes compare with the in situ observations. This is followed by a summary of the results in Sect. 4.

\section{Description of the model and observations}

The Met Office Unified Model (UM) version 8.5 is used to create a series of one-way nested simulations. The global model configuration GA6 (Walters et al., 2015) is the driving model, which uses the Even Newer Dynamics for Gen- 
eral atmospheric modelling of the environment (ENDGame) dynamical core (Wood et al., 2014). The global model has a resolution of $\mathrm{N} 512(\sim 25 \mathrm{~km})$ with 70 vertical levels and is run with a $10 \mathrm{~min}$ time step. The convection scheme is based on Gregory and Rowntree (1990) and uses a vertical velocity-dependent convective available potential energy (CAPE) closure. The Prognostic Cloud Prognostic Condensate (PC2) scheme of Wilson et al. (2008) is used with the microphysics scheme described by Wilson and Ballard (1999) but with numerous modifications including prognostic rain, cloud droplet settling and the Abel and Boutle (2012) rain drop size distribution. The boundary layer scheme used is based on Lock et al. (2000) and the radiative fluxes are determined by the Edwards and Slingo (1996) scheme. The global model is initialised at 00:00 UTC using the Australian Community Climate and Earth System Simulator (ACCESS; Puri et al., 2013) operational analysis for the case study date of 18 February 2014.

The first nested simulation within the global model is a $4 \mathrm{~km}$ grid length simulation. These simulations are run with a $100 \mathrm{~s}$ time step and are forced at the boundaries every $30 \mathrm{~min}$. At this resolution the Smith (1990) diagnostic cloud scheme is used where the critical relative humidity is 0.8 above $800 \mathrm{~m}$ and increases to 0.96 at the lowest model level. The cloud microphysical parameterisations are the same as the global model except that prognostic graupel is included and the generic ice particle size distribution (PSD) scheme of Field et al. (2007) is used. The convection scheme at this resolution has a modified CAPE closure that scales with grid box area, which allows for more of the convective activity to be modelled explicitly. The other difference from the global model is the diffusion. While there is no horizontal diffusion in the global model, in the $4 \mathrm{~km}$ model this is modelled by a Smagorinsky (1963)-type scheme and the vertical diffusion coefficients are determined using a scheme that blends those from the boundary layer scheme and the Smagorinsky scheme (Boutle et al., 2014). The older dynamics scheme (named New Dynamics; Davies et al., 2005) is used in the control model configuration, as that dynamical core was the one being used in the high-resolution operational model forecasts for this version of the model. However, the effects of the dynamics are also tested by using ENDGame in a sensitivity experiment.

A suite of $1 \mathrm{~km}$ simulations are nested in the $4 \mathrm{~km}$ simulation that investigates the effects of the dynamics, turbulence and microphysical parameterisations on the simulations of tropical convective clouds. There are 80 vertical levels and the model is run with a time step of $30 \mathrm{~s}$. The domain is $500 \times 500 \mathrm{~km}^{2}$ centred on the location of the Darwin radar $\left(12.25^{\circ} \mathrm{S}, 131.04^{\circ} \mathrm{E}\right)$ as shown in Fig. 1 and the convection is modelled explicitly. Given that the focus of this work is primarily on the cloud microphysics, a description of the scheme used in the model is provided, with the details of the other parameterisations available in the previously cited references. The microphysics scheme is described by Wil-

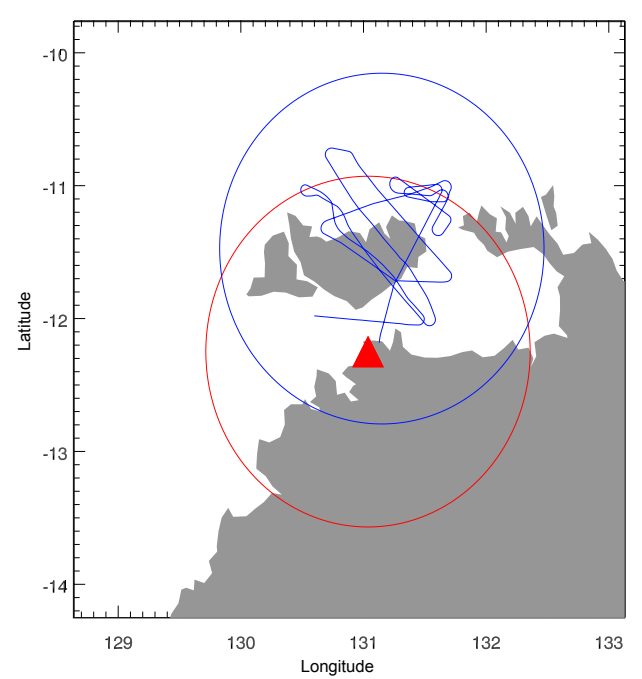

Figure 1. $1 \mathrm{~km}$ simulation domain with the radar location denoted by the red triangle and the $150 \mathrm{~km}$ range of the radar shown by the red circle. The aircraft flight track is shown by the blue line with the domain used in the aircraft comparison given by the blue circle.

son and Ballard (1999) but with numerous modifications. The single-moment scheme carries water in four variables: vapour, liquid, ice and rain, with an additional graupel variable in the 1 and $4 \mathrm{~km}$ simulations. The $4 \mathrm{~km}$ and control version of the $1 \mathrm{~km}$ model use the generic ice particle size distribution of Field et al. (2007), where the aggregates and crystals are represented by a single prognostic aggregate variable. This parameterisation is based on the idea of relating moments of the size distribution to the second moment, which is directly proportional to the ice water content when mass is equal to the square of the particle size. In using this parameterisation there is no need to specify an intercept parameter for the PSD and instead the microphysical transfer rates are derived from the moment estimation parameterisation that is a function of ice water content and temperature. The massdiameter relationships take the form of a power law.

$m(D)=a D^{b}$

The particle size distributions are generalised gamma functions.

$N(D)=N_{0} D^{\mu} e^{-\lambda D}$

where $N_{0}$ is the intercept parameter, $\mu$ is the shape parameter and $\lambda$ is the slope parameter. The coefficients for each hydrometeor species are given in Table 1, where the aggregate and crystal PSD coefficients are for the simulations that use an explicit PSD and not the generic ice PSD parameterisation. The explicit ice size distributions have a temperaturedependent intercept parameter that decreases with warming temperatures, representing larger particles and the effect of aggregation (Houze et al., 1979), where in Table 1 
Table 1. Parameters used to define the mass-diameter relationships (Eq. 1) and particle size distributions (Eq. 2), where $f(T)$ is given by Eq. (3).

\begin{tabular}{llrrrr}
\hline Parameter & Units & Rain & Aggregates & Crystals & Graupel \\
\hline$a$ & $\mathrm{~kg} \mathrm{~m}^{-b}$ & 523.56 & $2.3 \times 10^{-2}$ & $2.3 \times 10^{-2}$ & 261.8 \\
$b$ & & 3.0 & 2.0 & 2.0 & 3.0 \\
$N_{0}$ & $\mathrm{~m}^{-4}$ & $0.22 \lambda^{2.2}$ & $2 \times 10^{6} f(T)$ & $40 \times 10^{6} f(T)$ & $5 \times 10^{25} \lambda^{-4}$ \\
$\mu$ & & 0 & 0 & 0 & 2.5
\end{tabular}

$f(T)=\exp \left(-\frac{\max \left(T_{\mathrm{c}},-45^{\circ} \mathrm{C}\right)}{8.18^{\circ} \mathrm{C}}\right)$,

following Cox (1988) with $T_{\mathrm{c}}$ the temperature in degrees Celsius. Fall speeds are parameterised from power laws with the coefficients for crystals and aggregates from Mitchell (1996), graupel from Ferrier (1994) and rain from Abel and Shipway (2007).

Ice can be formed by homogeneous and heterogeneous nucleation processes. At $-40^{\circ} \mathrm{C}$ and below, homogeneous nucleation instantaneously converts all liquid water (both cloud water and rain) to ice. Heterogeneous nucleation requires cloud water to be present at temperatures at or below $-10^{\circ} \mathrm{C}$. The process is dependent on relative humidity and the mass of the number of active nuclei produced from the temperature-dependent function from Fletcher (1962). Once ice has been formed it can grow by vapour deposition, riming, collection and aggregation. The autoconversion of snow to graupel occurs when snow growth is dominated by riming, with the additional conditions that the snow mass threshold is exceeded and the temperature is below $-4{ }^{\circ} \mathrm{C}$. Once graupel has formed it grows by riming and collection. The ice hydrometeors experience sublimation, evaporation and melting. There are a number of graupel transfer terms that have not been included in the model as their rates are significantly smaller than the dominant processes (Wilkinson, 2013). The graupel terms not included are deposition and sublimation, wet mode growth, collection of ice crystals and heterogeneous freezing of rain by ice nuclei.

The control model (denoted by nd) in the set of $1 \mathrm{~km}$ simulations uses the New Dynamics and the sensitivity to dynamical formulation is investigated by testing the ENDGame dynamical core in the simulation denoted eg. Modelling the vertical turbulent mixing using the 3-D Smagorinsky scheme rather than the blended scheme used in the control simulation is labelled $3 \mathrm{~d}$. The other experiments test aspects of the microphysical parameterisations:

- nopsd - rather than use the generic ice PSD as in the control experiment, explicit PSDs are used for ice where the single ice prognostic is diagnostically split as a function of the temperature difference from cloud top into two categories to represent the smaller more numerous ice crystals and larger aggregates (Wilkinson, 2013);
- qcf2 - as for nopsd but the crystals and aggregates are represented as two separate prognostic variables;

- qcf2hm - as for qcf2 but with the inclusion of an ice splintering parameterisation that increases the deposition rate in the Hallett and Mossop (1974) temperature zone of -3 to $-8^{\circ} \mathrm{C}$. This parameterisation represents the increase in the ice particle number concentration due to ice splinter production during riming and is dependent on the supercooled liquid water content, and as such the riming rate, as well as the temperature that allows for increased deposition at temperatures colder than $-8^{\circ} \mathrm{C}$ due to the vertical transport of ice splinters (Cardwell et al., 2002);

- qcf2ndrop500 - as for qcf2 but with an increase in the cloud droplet number concentration from 100 to $500 \mathrm{~cm}^{-3}$;

- qcf2sr2graupel - as for qcf2 but with the restriction that snow-rain collisions do not produce graupel;

- qcf2noqgr - as for qcf2 but without the inclusion of graupel;

- qcf2rainfreeze - as for qcf2 but with the inclusion of a heterogeneous rain-freezing parameterisation based on the stochastic parameterisation of Bigg (1953) following Wisner et al. (1972). This process represents the heterogeneous freezing of rain by heterogeneous nucleation by ice nuclei;

- qcf2raindsd - as for qcf2 but with the Marshall and Palmer (1948) rain drop size distribution.

The Darwin C-band polarimetric (CPOL) radar (Keenan et al., 1998) collects a 3-D volume of observations out to a range of $150 \mathrm{~km}$. The radar observations have been interpolated onto the model $1 \mathrm{~km}$ grid, and the analysis of radar reflectivities is for the area encompassed by the radius $<150 \mathrm{~km}$ from the radar (see Fig. 1). The precipitation rates derived from the radar reflectivity have uncertainties of $25 \%$ at rain rates greater than $10 \mathrm{~mm} \mathrm{~h}^{-1}$ and $100 \%$ for the lowest rain rates (Fridlind et al., 2012). The satellite observations of outgoing longwave radiation (OLR) and ice water path (IWP) were derived from the geostationary satellite MTSAT-1R following Minnis and Smith (1998) and Minnis et al. (2008, 
2011). Observations from the French Falcon 20 aircraft include the IWC measurement made with the isokinetic evaporator probe IKP-2 (Davison et al., 2009), and the ice particle size distribution reconstructed from images of individual particles from the 2-D stereo (Lawson et al., 2006) and precipitation imaging probes (Baumgardner et al., 2001). The particle probes were fitted with anti-shattering tips and the processing of the size observations accounted for any possible remaining ice shattering by consideration of the interarrival times and the ratio between the particle surface and lengths (Leroy et al., 2015). Since the IKP-2 measures the total water content, liquid water and water vapour contributions should be subtracted to obtain IWC. Unfortunately, the hot-wire liquid water content (LWC) sensor on the aircraft was unable to measure LWC below about $10 \%$ of the IWC in mixed-phase conditions, and LWC levels exceeding this value were very rare. Fortunately the Goodrich Ice Detector could be used to detect the presence of liquid water. Two such regions in two very short flight segments for this case, research flight 23 , were identified at $-10^{\circ} \mathrm{C}$, and these regions have been excluded from the analysis. The minimum detectable IWC of the IKP-2 is determined by the noise level of the water vapour measurements of the IKP-2 and background probes. This resulting noise level of the subtraction of the background humidity from the IKP-2 humidity is a function of temperature: it is about $0.1 \mathrm{~g} \mathrm{~m}^{-3}$ at $-10^{\circ} \mathrm{C}$, dropping rapidly to about $0.005 \mathrm{~g} \mathrm{~m}^{-3}$ at $-50^{\circ} \mathrm{C}$. Since most data were taken at temperatures colder than about $-25^{\circ} \mathrm{C}$, a minimum IWC of $0.05 \mathrm{~g} \mathrm{~m}^{-3}$ was chosen as the threshold to include in our analysis.

Two sources of vertical velocity are used from the Falcon 20. Position, orientation and speed of the aircraft are measured by a GPS-coupled inertial navigation system. The 3$\mathrm{D}$ air motion vector relative to the aircraft is measured by Rosemount 1221 differential pressures transducer connected to a Rosemount 858 flow angle sensor mounted at the tip of the boom, ahead of the aircraft and by a pitot tube which is part of the standard equipment of the aircraft. Wind in local geographical coordinates is computed as the sum of the air speed vector relative to the aircraft and the aircraft velocity vector relative to the ground. Both computations use classical formulas in the airborne measurement field described in Bange et al. (2013). The other vertical air velocity measurement used is retrieved from the multibeam cloud radar observations using the 3-D wind retrieval technique described in Protat and Zawadzki (1999), and we use the technique described in Protat and Williams (2011) to separate terminal fall speed and vertical air velocity. Comparisons near flight altitude with the aircraft in situ vertical velocity measurements show that the vertical velocity retrieval is accurate to within $0.3 \mathrm{~m} \mathrm{~s}^{-1}$. All observations are averaged to the model $1 \mathrm{~km}$ grid and exclude observations when the aircraft roll angle exceeds $5^{\circ}$.

\section{Comparison of the simulations with observations}

On 18 February 2014 the monsoon trough was stalled near the base of the Top End with active conditions continuing about the northern coast. There was a deep moisture layer and low-level convergence that produced a mesoscale convective system. At 14:30 UTC, satellite imagery shows the convection around Darwin was somewhat isolated in nature, with a convective cell developing close to the radar (Fig. 2). This convection developed into a larger organised oceanic mesoscale convective system by 18:00 UTC with deep convective cells producing cloud top temperatures of $-80^{\circ} \mathrm{C}$. A widespread region of anvil cloud produced from the outflow of deep convection was seen to develop from 18:00 UTC and persist for over $8 \mathrm{~h}$. The HIWC research flight penetrated convective cores in a region north-east of the radar at 22:00-24:00 UTC (Fig. 1) with peak ice water content up to $5 \mathrm{~g} \mathrm{~m}^{-3}$ at $1 \mathrm{~s}$ resolution. There was almost no supercooled water detected during the flight, even at $-10^{\circ} \mathrm{C}$, and graupel was intermittently observed. The absence of supercooled water coupled with the occasional presence of graupel is due to the system being sampled at the mature-decaying stage, where the supercooled water had been consumed in the production of graupel. Most of the time the particle images were of dense ice aggregates at flight level, except within some convective cores where graupel was observed, as also indicated by strong W-band attenuation.

Comparison of the modelled outgoing longwave radiation (OLR) with the satellite observations in Fig. 2 show that in general, the control simulation represents the life cycle of the MCS fairly well. The location of the mostly oceanic convective cells look reasonable; however, the modelled MCS is larger and composed of more numerous and deeper convective clouds than what was observed in the pixel-level satellite OLR data and seen in the low-level radar reflectivity fields shown in Fig. 3. The model also produces more convection over the Tiwi Islands than what was observed at 17:30 UTC. As the MCS transitions from a developing-mature system through to a mature-decaying system, the observed reduction of deep convective cells with time is simulated, although the OLR remains significantly underestimated. During the research flight at 23:30 UTC, the modelled MCS shows cloud positioned in a similar location to that observed with respect to the MCS structure; however, the modelled cloud is shifted somewhat to the north-east (Fig. 2h, 1).

The mean precipitation rates and ice water path (IWP) (Fig. 3) calculated for the radar domain shown in Fig. 1 demonstrate that a larger IWP implies a larger surface rainfall rate as seen in previous tropical studies (e.g. Liu and Curry, 1999). The radar-derived precipitation shows that the simulations overestimate the domain mean rainfall rate during the development stages of the MCS and produce the peak in precipitation about $2 \mathrm{~h}$ earlier than is observed. The model precipitation maximum occurs when the simulated convection is strongest, as measured by the largest domain mean 
(a)

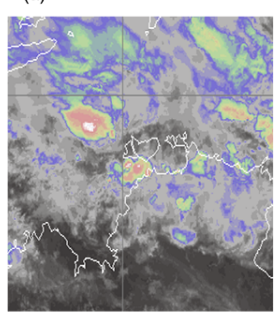

(e) olr obs $14: 30$

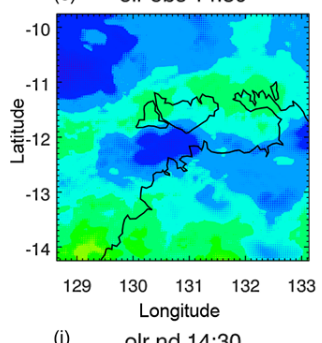

(i) olr nd 14:30
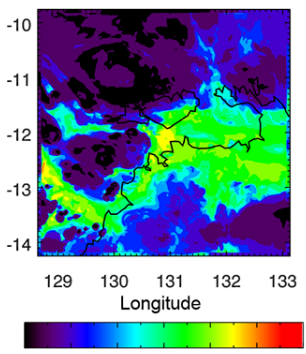

$\begin{array}{llllllllllll}100 & 140 & 180 & 220 & 260 & 300\end{array}$ (b)

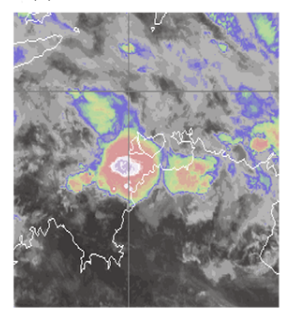

(f) olr obs 17:30
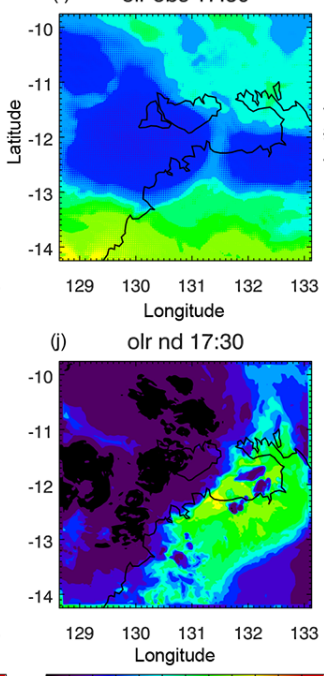

(c)

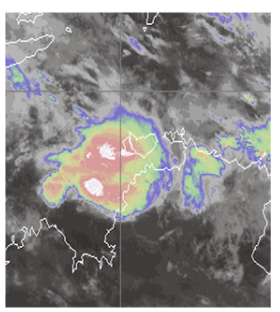

(g) olr obs 20:30

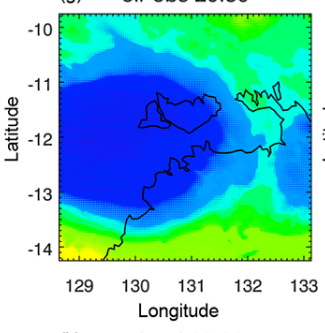

(k) olr nd 20:30

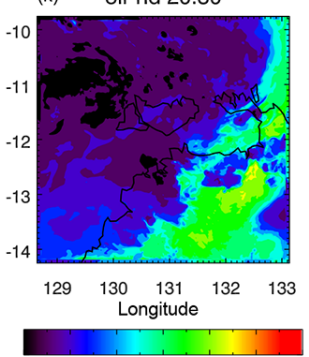

(d)

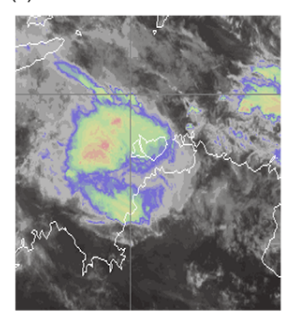

(h) olr obs 23:30

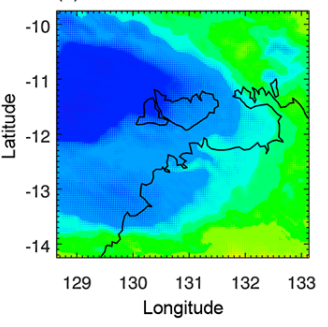

(I) olr nd 23:30

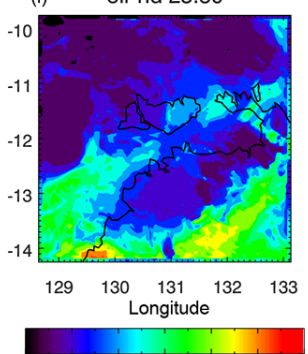

Figure 2. Top row: time series of enhanced infrared satellite imagery over the Darwin region on 18 February 2014: (a) 14:30, (b) 17:30, (c) 20:30 and (d) 23:30 UTC. The temperatures range from $230 \mathrm{~K}$ in blue through to $190 \mathrm{~K}$ in white and purple. Middle row: time series of observed outgoing longwave radiation centred on the Darwin radar, where the pixel-level satellite data have been interpolated onto the $1 \mathrm{~km}$ model grid. Last row: as above, but for the modelled outgoing longwave radiation from the control experiment, labelled nd.

vertical velocity at $500 \mathrm{hPa}$ and the maximum vertical velocities. The observed domain mean rainfall maximum corresponds to the time when the domain mean cloud top height is highest (not shown) and, together with the infrared satellite imagery (Fig. 2), suggests that the generation of significant anvil cloud occurs before the domain mean precipitation maximum, rather than when the convection is strongest as is the case in the simulations. Note that the simulated domain mean precipitation rate at both the earlier and later times is outside of the uncertainty range of the radar-derived rainfall rate (Fridlind et al., 2012).

The underestimate in modelled surface rainfall for the later times when the MCS has matured is not due to an underestimate in the domain mean upper tropospheric cloud cover, as both the model and satellite observations show mostly overcast conditions, but rather the underestimate in condensate reaching below the freezing level (Fig. 3f). The observed IWP is only valid for the daytime from about 22:30 UTC or 08:00 local time and, while the simulations with the generic PSD parameterisation compare well with the satellite-derived value, the comparison of VISST (Visible Infrared Solar-Infrared Split Window Technique)-derived IWP with CloudSat in tropical regions was shown by Waliser et al. (2009) to be underestimated by $25 \%$, likely due to the maximum retrieved optical depth being limited to 128 . Together with the CloudSat uncertainties (30 bias and $80 \%$ root mean square error; Heymsfield et al., 2008), this suggests that the modelled domain mean IWP may be underestimated from 22:30 to 23:30 UTC. Other studies have documented the lack of stratiform rainfall in convective-scale simulations and some attributed the error to excessive evaporation in single-moment microphysics schemes that use a constant intercept parameter in the rain DSD (drop size distribution) (Morrison et al., 2009). That is not the case in this work and rather the cause is likely due to overly strong convection (Figs. 2 and 3d) that detrains too high and does not produce enough condensate in the lower stratiform regions as has been shown by Ferrier et al. (1996), Tao et al. (1993) and Morrison et al. (2009).

The greater IWP in the simulations that use the generic ice PSD parameterisation is associated with larger relative humidity in the upper troposphere (Fig. 4a: nd, eg, 3d). In a study comparing different microphysics schemes, VanWeverberg et al. (2013) found the same result and associated 

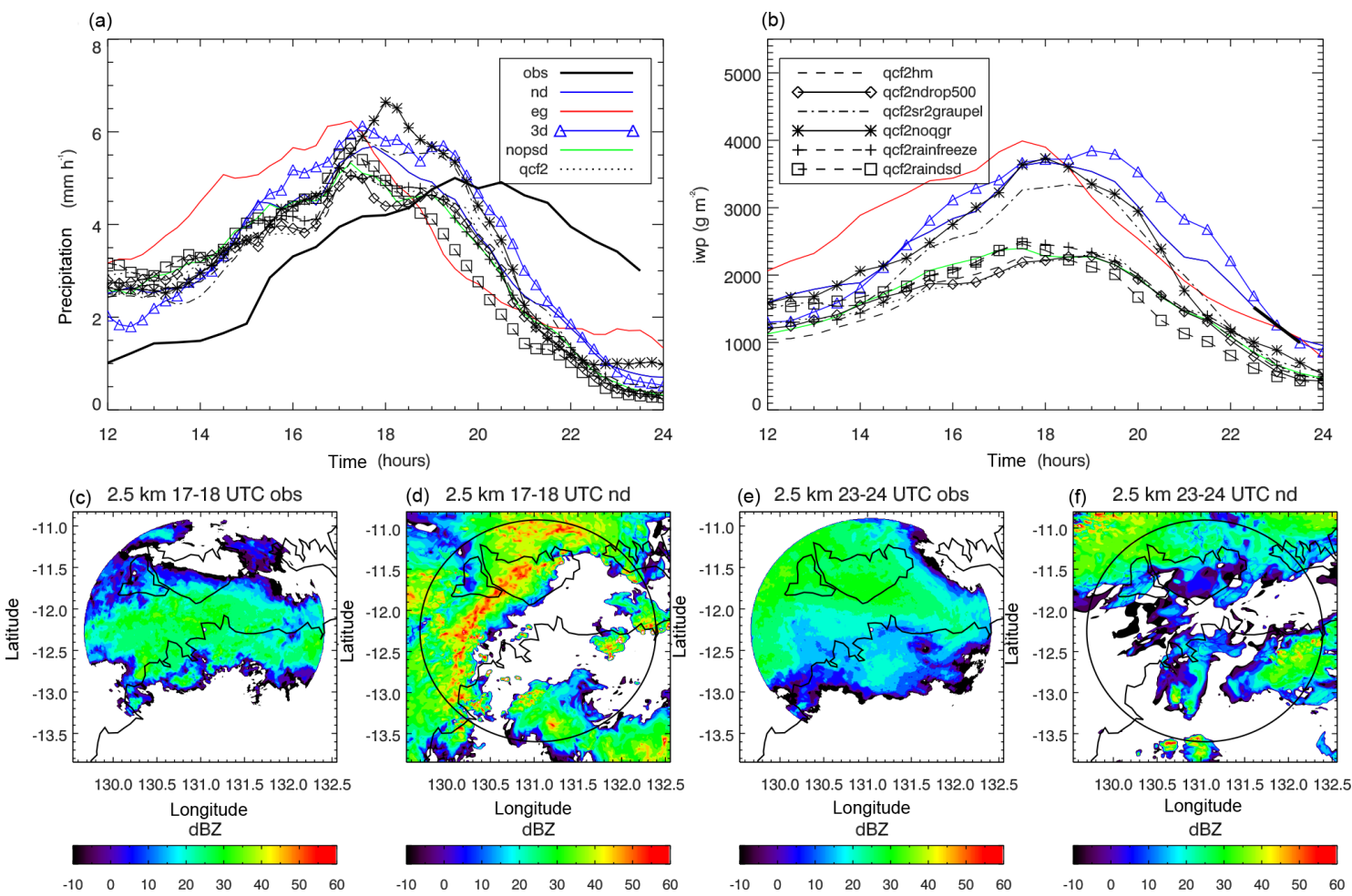

Figure 3. Time series of domain mean: (a) precipitation $\left(\mathrm{mm} \mathrm{h}^{-1}\right)$ and (b) ice water path $\left(\mathrm{g} \mathrm{m}^{-3}\right)$. The observations are from the CPOL radar in (a) and the satellite retrieval in (b); note that the observed IWP is only plotted from 22:30 to 23:30. The time period spans 12:0024:00 UTC on 18 February 2014. (c) 2.5 km observed radar reflectivity averaged over 17:00-18:00 UTC. (d) As in (c) except for the modelled reflectivity from the control simulation (nd), (e) as in (c) except for 23:00-24:00 UTC, (f) as in (d) except for 23:00-24:00 UTC.

the increased moisture with the sublimation of ice particles due to the scheme with the slowest ice fall speeds producing the greatest condensate and moisture. That is not the case for this current study where the larger IWP and relative humidity is produced by the microphysics configuration that produces larger mean mass-weighted particle sizes (Fig. 4c) but similar ice fall speeds above about $12 \mathrm{~km}$ and faster speeds below this height. Figure $4 \mathrm{~b}$ shows the fall speeds for the ice crystals and aggregates/snow particles. All simulations use the same formulation for snow and, even though the generic PSD only represents a single hydrometeor category, there are two fall speeds used to enable a representation of both fast and slow sedimenting particles based on size. The method when using the generic PSD is described by Furtardo et al. (2014) where, for narrow size distributions and small mean sizes, the fall speed used is that shown for the ice crystals in Fig. 4b, and for broader size distributions and larger mean sizes the snow fall speed is used (the crossover is around $600 \mu \mathrm{m}$ ). Looking at the mean mass-weighted ice diameters in Fig. 4c and $d$ shows larger sizes for the simulations that use the generic PSD; however, the slower ice crystal fall speed used in these cases produces a similar mean fall speed to the simulations that use two ice prognostics.

The higher RH in the simulations using the generic ice PSD could be due to the larger, faster falling particles in the levels below $12 \mathrm{~km}$, removing more of the LWC via riming, which would allow for greater supersaturation. To be able to conclude this with certainty would require additional experiments that isolate individual processes, something that is beyond the scope of this study; however, the subsequent results to be presented support this possible line of thinking. More riming would release more latent heat, which, along with the larger ice particles being more effectively offloaded, could lead to the generation of stronger updraughts with less entrainment and higher RH in the upper troposphere. This is illustrated in the convective updraught $\left(>1 \mathrm{~m} \mathrm{~s}^{-1}\right)$ horizontal mass divergence profiles shown in Fig. 5a. As discussed by Yuter and Houze Jr. (1995), the presence of decelerating updraughts and accelerating downdraughts can be largely explained by entrainment. Entrainment reduces the buoyancy of updraughts, slowing and eventually stopping the air parcel, which is where divergence is expected. In contrast, entrainment into downdraughts enhances evaporative cooling, increasing the downward mass transport and convergence. Note that above $16 \mathrm{~km}$ the vertical velocities show oscillatory motions consistent with gravity waves; therefore, above this height the mass divergence appears to be driven by these waves.

Figure 5a shows that horizontal mass divergence in the mixed-phase regions of the convective updraughts is the most 

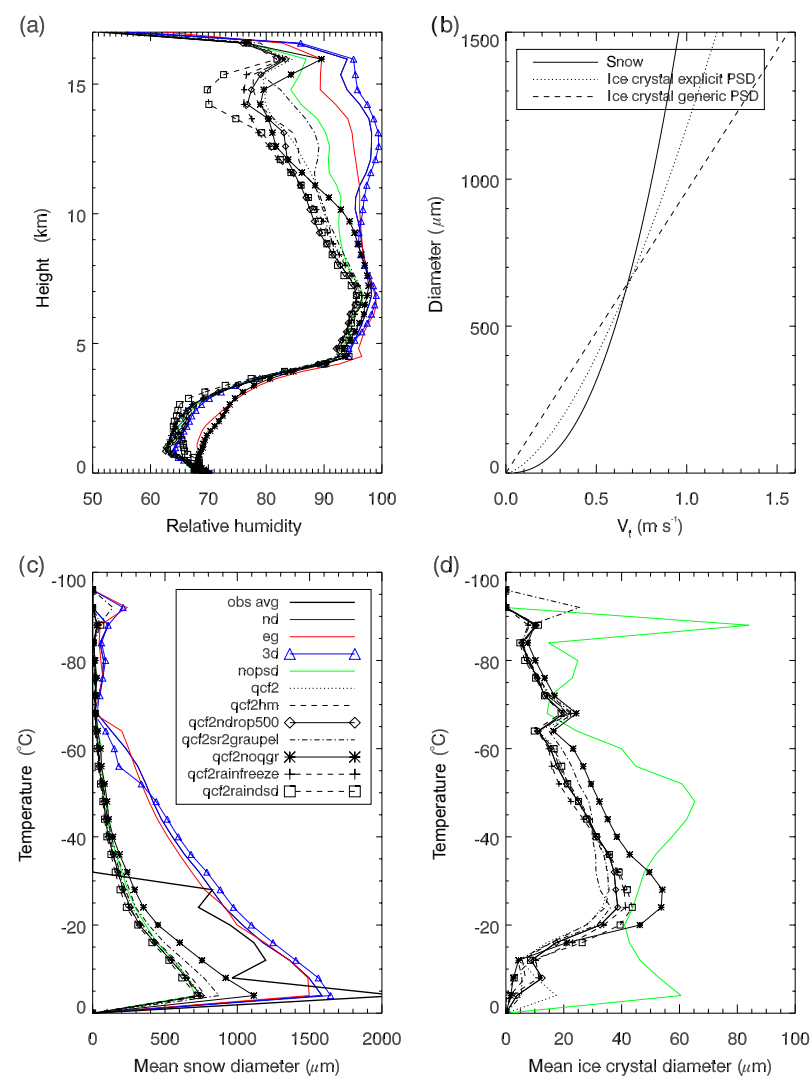

Figure 4. (a) Simulated relative humidity is for the area encompassed by the $150 \mathrm{~km}$ radius centred on the Darwin radar on 18 February 2014 from 23:00 to 24:00 UTC. (b) Ice fall speeds $\left(\mathrm{m} \mathrm{s}^{-1}\right)$ as a function of diameter $(\mu \mathrm{m})$ for the snow category and the ice crystals used in the simulations with the explicit and generic PSD, see text for details. (c) Mean mass-weighted snow diameter $(\mu \mathrm{m})$ as a function of temperature $\left({ }^{\circ} \mathrm{C}\right)$ where the observations are from the aircraft and have been averaged to be representative of a $1 \mathrm{~km}^{2}$ grid cell. (d) As for (c) except for the mean mass-weighted ice crystal diameter $(\mu \mathrm{m})$.

sensitive to the turbulence formulation in the model, with the simulation with greater turbulent mixing (3d) showing greater mass divergence, indicative of greater entrainment, in the range of $5-8 \mathrm{~km}$. This contrasts with the upper iceonly regions of the convective updraughts that show that the largest control on horizontal mass divergence is the ice sizes. The simulations with smaller sized particles have more mass divergence above $12 \mathrm{~km}$, indicating more entrainment and a larger reduction in the buoyancy in the upper levels of convective updraughts than the simulations with larger sized ice particles. This is confirmed by examining the convective updraught buoyancy properties at $14 \mathrm{~km}$ shown in Fig. $5 \mathrm{~b}$ and c. The buoyancy, $\Delta \theta_{\mathrm{d}}$, is calculated from the difference in the density potential temperature (which includes condensate) from the slab mean for the convective updraughts with vertical velocity $>1 \mathrm{~m} \mathrm{~s}^{-1}$. Comparing the equivalent potential temperature as a function of $\Delta \theta_{\mathrm{d}}$ at $14 \mathrm{~km}$ (Fig. 5b) between simulations with larger (3d) and smaller (qcf2) ice sizes shows that for the positively buoyant updraughts, the simulation with smaller ice sizes has fewer occurrences of high $\theta_{\mathrm{e}}$. This gives support to the argument derived from the convective updraught horizontal mass divergence that entrainment is larger in the upper ice-only convective updraughts when the ice sizes are smaller, although we do note that some of this difference could be due to differences in freezing. To analyse this in more detail, the histogram of convective updraught buoyancy (Fig. 5c) shows a greater number of occurrences of more positively buoyant clouds at $14 \mathrm{~km}$ for the simulations that have larger sized ice particles, supporting the argument that less horizontal mass divergence represents less entrainment with more positively buoyant updraughts that penetrate higher (as confirmed by examining the cloud top height distributions; not shown). Similarly, comparing $\theta_{\mathrm{e}}$ as a function of $\Delta \theta_{\mathrm{d}}$ at $6 \mathrm{~km}$ between the control simulation (nd) and the one that increases turbulent mixing (3d) shows that the case with greater mixing has significantly more occurrences of low $\theta_{\mathrm{e}}$, consistent with greater entrainment. Note that the increased number of occurrences of positively buoyant convective updraughts at $6 \mathrm{~km}$ in the $3 \mathrm{~d}$ simulation is due to the increased cloudiness at these levels as shown in Fig. 6 and discussed in the next section.

\subsection{Radar reflectivity characteristics}

The model hydrometeor fields have been converted into radar reflectivities by assuming Rayleigh scattering, with no consideration of the effects of attenuation or attempt to model the radar bright band. Due to the long wavelength of the CPOL radar $(5.3 \mathrm{~cm})$, modelled reflectivity is calculated following Hogan et al. (2006) where the reflectivity is considered proportional to mass squared

$Z=R \int_{0}^{\infty} M(D)^{2} N(D) \mathrm{d} D$,

where $R=10^{18} \frac{|K|^{2}}{0.93}\left(\frac{6}{\pi \rho}\right)^{2}, \rho$ is the particle density and the mass $M$ and particle size distribution $N(D)$ are defined by Eqs. (1) and (2). For cloud liquid water the reflectivity is calculated from the constant number concentration of $100 \mathrm{~cm}^{-3}$ in the simulations with the size distribution $N(D)=P D^{2} \exp ^{-\lambda D}$, where $P=N / 2 \lambda^{3}$ following McBeath et al. (2014). The dielectric factor $|K|^{2}$ is set to 0.93 for water and 0.174 for ice. The particle densities used in the calculation of $R$ are $1000 \mathrm{~kg} \mathrm{~m}^{-3}$ for rain, $917 \mathrm{~kg} \mathrm{~m}^{-3}$ for aggregates and crystals and $500 \mathrm{~kg} \mathrm{~m}^{-3}$ for graupel. For the simulations that use the generic ice PSD parameterisation, the aggregate reflectivity is proportional to the fourth moment of the PSD, which is calculated from the Field et al. (2007) moment estimation parameterisation. 
(a)

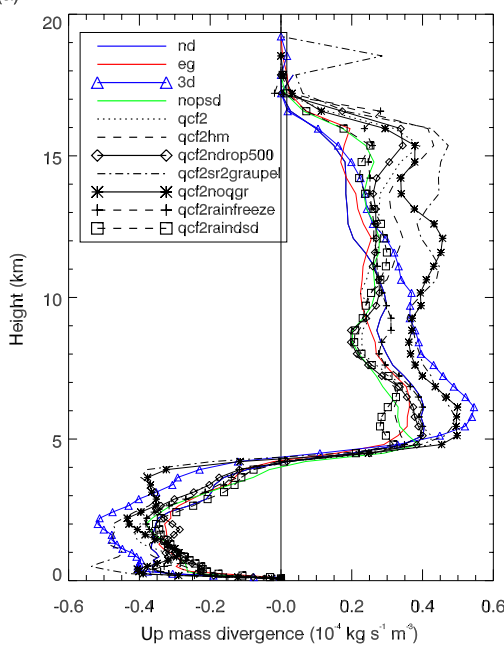

(b)

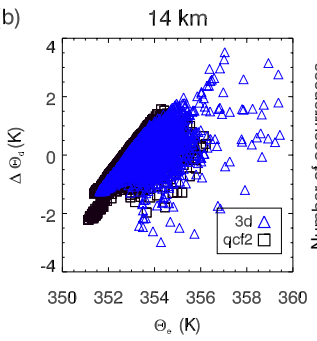

(d)

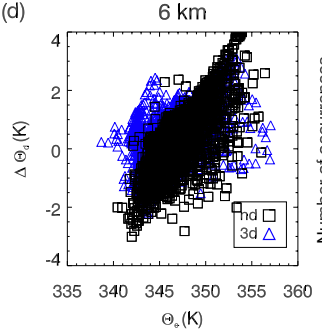

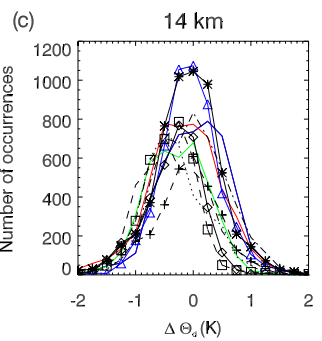

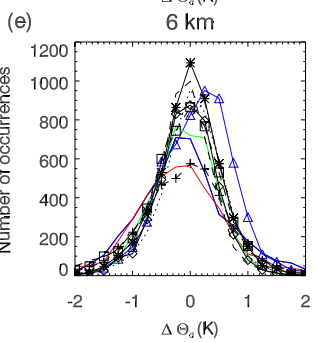

Figure 5. (a) Vertical profile of convective updraught $\left(>1 \mathrm{~m} \mathrm{~s}^{-1}\right)$ mean horizontal mass divergence $\left(10^{-4} \mathrm{~kg} \mathrm{~s}^{-1} \mathrm{~m}^{-3}\right)$ at 18:00 UTC. (b) Scatter plot of $\theta_{\mathrm{e}}$ against $\Delta \theta_{\mathrm{d}}$ at $14 \mathrm{~km}$ for two simulations that change the turbulent mixing (3d), and add an additional ice prognostic variable and have smaller ice sizes (qcf2). (c) Histogram of $\Delta \theta_{\mathrm{d}}$ at $14 \mathrm{~km}$. (d) As in (b) except for $6 \mathrm{~km}$ and comparing the control (nd) and the $3 \mathrm{~d}$ simulations and (e) as in (c) except for $6 \mathrm{~km}$. See text for details.

\subsubsection{Statistical radar coverage analysis}

To examine the temporal evolution of the mesoscale convective system and evaluate the modelled MCS life cycle and the simulated reflectivities, a statistical coverage product has been produced following May and Lane (2009). The data used to construct the statistical product are reflectivity fields from CPOL and the simulations every $30 \mathrm{~min}$ for $12 \mathrm{~h}$ from 12:00 to 24:00 UTC. At each height the fraction of the total area within the radar domain covered by reflectivity thresholds is calculated, with the thresholds chosen as 10, 20, 30 and $40 \mathrm{dBZ}$.

The observed statistical radar coverage product shown in Fig. 6 illustrates the development of the MCS. At 12:00 UTC the radar domain has a low fractional area coverage of up to 0.15 for the $10 \mathrm{dBZ}$ threshold, showing that at 12:00 UTC there were radar-detectable hydrometeors covering 5-15\% of the radar sampling area between the lowest detectable altitude of 1.5 and $8 \mathrm{~km}$. Highest reflectivity echo tops of $11 \mathrm{~km}$ are seen in the $>10 \mathrm{dBZ}$ fractional coverage at 17:30 UTC, which coincides with the time that the very cold cloud tops associated with deep convective cells were seen in the satellite imagery (Fig. 2). The maximum coverage of the domain by hydrometeors with reflectivities $>10 \mathrm{dBZ}$ is $85 \%$, seen at 21:00-22:00 UTC, which is when the large anvil cloud shield appears a few hours after the deepest convection occurs. The observed areas of reflectivity $>10 \mathrm{dBZ}$ are fairly uniform with height from 2 to $6 \mathrm{~km}$, demonstrating little variability of the reflectivity echo coverage from the low levels to a couple of kilometres above the freezing level. Fractional areas larger than 0.05 with reflectivities $>20 \mathrm{dBZ}$ are mostly confined to below $6 \mathrm{~km}$, with the maximum fraction of 0.65 occurring at 21:00 UTC at $4 \mathrm{~km}$. The $>30 \mathrm{dBZ}$ area is not greater than $10 \%$ until 16:00 UTC and is maximum between 20:30 and 22:00 UTC at $4 \mathrm{~km}$ with a value of 0.35 . There is no fractional area of the domain $>0.05$ that contains observed reflectivities greater than $40 \mathrm{dBZ}$.

While the statistical radar coverage product produced for the control simulation, nd, does show a transition to widespread stratiform cloud regions, as shown by the peak $<10 \mathrm{dBZ}$ coverage at 21:00 UTC and predicts the timing of the deepest clouds generally well (Fig. 6), there are clear deficiencies in the simulated evolution of the MCS. There are much larger high dBZ fractional areas, deeper clouds occur too early in the simulation and there is a strong vertical gradient in the area coverage with height. The less uniform vertical area coverage shows that the simulated clouds have more variability in reflectivity with height compared to the observations. In coarse-resolution models, a common model error is too little detrainment at the freezing level (e.g. Franklin et al., 2013); however, in this convection-permitting simulation the change in hydrometeor area with height is mainly due to too little stratiform cloud and rain area, which explains the reduction in area below the melting level and the convective-stratiform-modelled ratio being skewed towards more convection than is observed (discussed in Sect. 3.1.3).

A clear difference between the observations and the simulation is the $>20 \mathrm{dBZ}$ reflectivity areas above the freezing level. The observations show some hydrometeors present $1-2 \mathrm{~km}$ above the freezing level that have reflectivities $>20 \mathrm{dBZ}$, but no areas that meet the minimum threshold of $5 \%$ that have reflectivities $>30$ or $40 \mathrm{dBZ}$. The simulation 

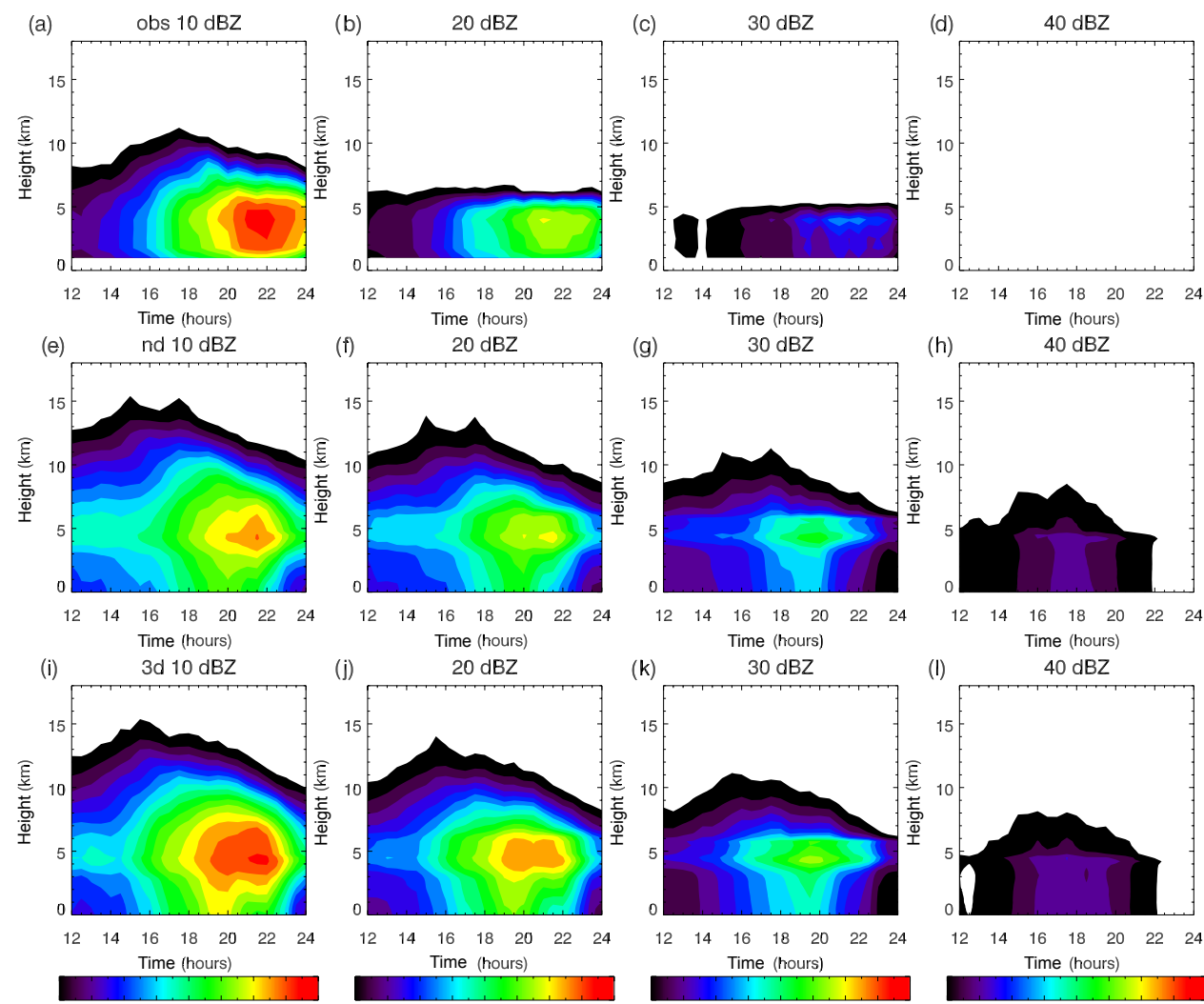

0.050 .150 .250 .350 .450 .550 .650 .750 .850 .050 .150 .250 .350 .450 .550 .650 .750 .850 .050 .150 .250 .350 .450 .550 .650 .750 .850 .050 .150 .250 .350 .450 .550 .650 .750 .85

Figure 6. The observed (top panels), simulated by the control model (middle panels) and with a change to the turbulent mixing (lower panel) fraction of radar-detected area covered by reflectivities greater than (a, e, i) $10,(\mathbf{b}, \mathbf{f}, \mathbf{j}) 20$, (c, g, k) 30 and (d, h, l) $40 \mathrm{dBZ}$ for 12:00-24:00 UTC on 18 February 2014.

on the other hand shows $>20 \mathrm{dBZ}$ fractional areas $>0.6$ indicative of larger ice particles in the model than in the observations, which will be explored in detail later. The simulated reflectivity area $>30 \mathrm{dBZ}$ above $5 \mathrm{~km}$ is due to the presence of both ice and rain, and the $>40 \mathrm{dBZ}$ areas are almost exclusively due to rain. The simulated rain above the freezing level that is not observed suggests that the model has faster updraughts than observed, which loft large rain particles upwards, and/or the heterogeneous freezing of rain that is not represented in the model is an important process in tropical convection and/or other errors exist in the representation of the rain DSD. This result is what motivated the experiment with the addition of a heterogeneous rain-freezing parameterisation, as observations in oceanic convection have shown that most drops freeze between about -6 and $-18^{\circ} \mathrm{C}$ (Stith et al., 2002, 2004; Heymsfield et al., 2009).

All simulations show the same main errors in the statistical radar coverage as the control case, nd. The simulation that uses a differing turbulent mixing formulation (3d) produces the closest representation of the observed fractional areas for the dBZ thresholds of 10 and $20 \mathrm{dBZ}$ in the larger areas below the melting level (Fig. 6i, j). This can likely be attributed to greater horizontal mass divergence between 5 and $8 \mathrm{~km}$ at the earlier convective times (Fig. 5), indicative of increased entrainment and mixing of environmental air in this simulation, which acts to increase the amount of IWC (Figs. 3 and 13) and the area of precipitation.

\subsubsection{Contoured frequency by altitude diagrams}

The CPOL contoured frequency by altitude diagram (CFAD) using the observations from 23:00 to 24:00 UTC every $30 \mathrm{~min}$ exhibits a fairly narrow distribution at the heights above the freezing level, with the altitude range of $12-13 \mathrm{~km}$ having little variability, reflecting the dominance of small ice particles growing primarily by deposition in the uppermost cloud levels (Fig. 7a). Below $10 \mathrm{~km}$ the distribution shows increasing reflectivity with decreasing height as particles grow rapidly through aggregation, with reflectivities centred on the modal value of $10 \mathrm{dBZ}$. At altitudes below the melting level the distribution widens and the reflectivities extend from 5 to $35 \mathrm{dBZ}$ with the largest occurrences around $30 \mathrm{dBZ}$. The lack of a predominant bright band in the observations is likely due to the data being collected from volumetric scans; however, 
(a)
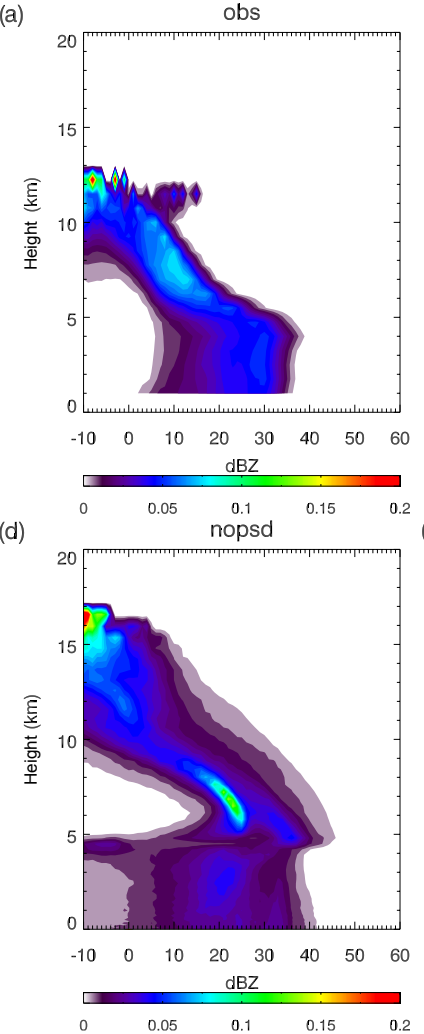

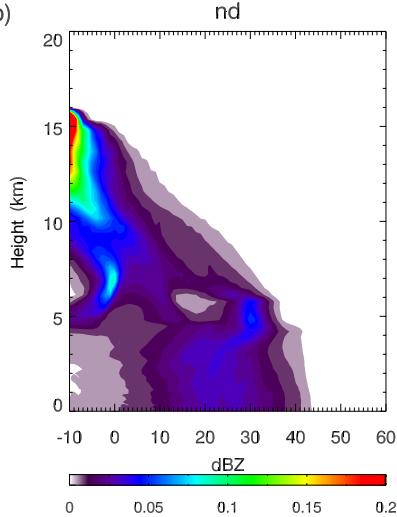

(e)

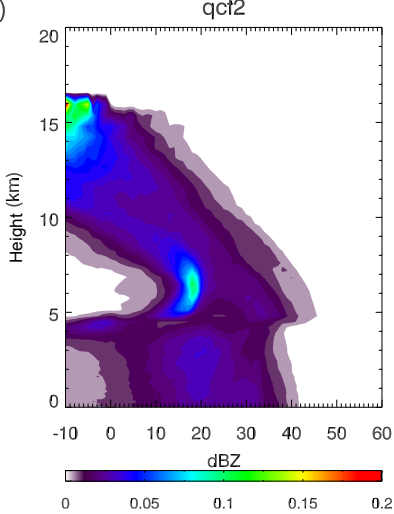

(c)
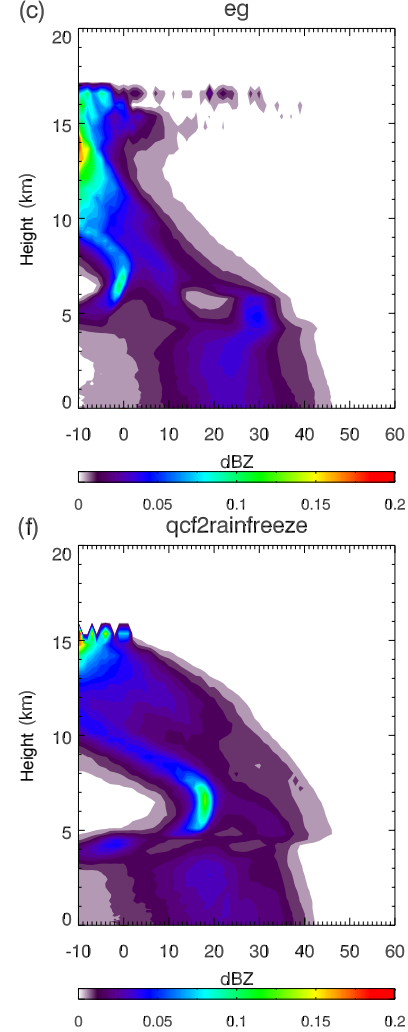

Figure 7. Contoured frequency with altitude diagrams of radar reflectivity for the region within 150 km of the radar for the times 23:0024:00 UTC. (a) Observations, (b) control simulation, (c) ENDGame dynamical core simulation, (d) no use of the generic ice PSD parameterisation, (e) additional ice prognostic and (f) inclusion of heterogeneous rain-freezing parameterisation. See text for details on different simulations.

there are slightly higher reflectivities seen at $4 \mathrm{~km}$ indicating a bright band.

The simulations all show the common errors of clouds within these reflectivity regions extending too high, reflectivities that are too large between 4 and $6 \mathrm{~km}$, greater reflectivity range below $4 \mathrm{~km}$ and disjointed profiles due to separate hydrometeor categories. The simulations show more of a convective-type profile with broader distributions above the freezing level compared to the observations. The more numerous high-reflectivity outliers in the simulations indicate a larger number of deep convective cells and/or a smaller proportion of convective-stratiform area.

The simulation with the different dynamical core, ENDGame (eg) shown in Fig. 7c, shows higher clouds and a broader range of reflectivities at $14-16 \mathrm{~km}$. This latter result suggests the presence of large particles being lofted into the upper cloud levels by intense convective cores, as can be seen by the $40 \mathrm{dBZ}$ reflectivities at $17 \mathrm{~km}$. The observations do show some sign of this lofting occurring at $11-12 \mathrm{~km}$; however, the reflectivities are constrained to be $<20 \mathrm{dBZ}$. This feature can also be seen in the cases that include the ice splintering process, the limited graupel case and the increased droplet number concentration case (not shown). The simula- tions that use the generic ice PSD parameterisation (Fig. 7b and c; nd and eg) overestimate the occurrence of low reflectivities above $10 \mathrm{~km}$ and have a modal reflectivity at $6-8 \mathrm{~km}$ that is too low compared to the observations. Using explicit ice PSDs produces a closer match to the observed reflectivity distribution above $10 \mathrm{~km}$, although the simulated clouds still have greater vertical extent, and the modal value of the reflectivities at $6-8 \mathrm{~km}$ with the explicit PSDs is approximately $5 \mathrm{dBZ}$ too large (nopsd, qcf2). The inclusion of a heterogeneous rain-freezing parameterisation reduces the number of occurrences of reflectivities $>20 \mathrm{dBZ}$ between 5 and $10 \mathrm{~km}$ and reduces the cloud top heights (qcf2rainfreeze). Both of these results agree better with the observations suggesting that this process may be important in tropical convective cloud systems. However, given the errors in the dynamics and microphysics in the model for this case, further study is required to better understand the effects of this process. Even in the simulation without graupel, the reflectivities are overestimated at the melting level (not shown) and this is due to the ice aggregate PSD.

Focussing on the $2.5 \mathrm{~km}$ reflectivity distribution shown in Fig. 8a allows an evaluation of the rain properties from the simulations, in particular the rain DSD. All simula- 
(a)

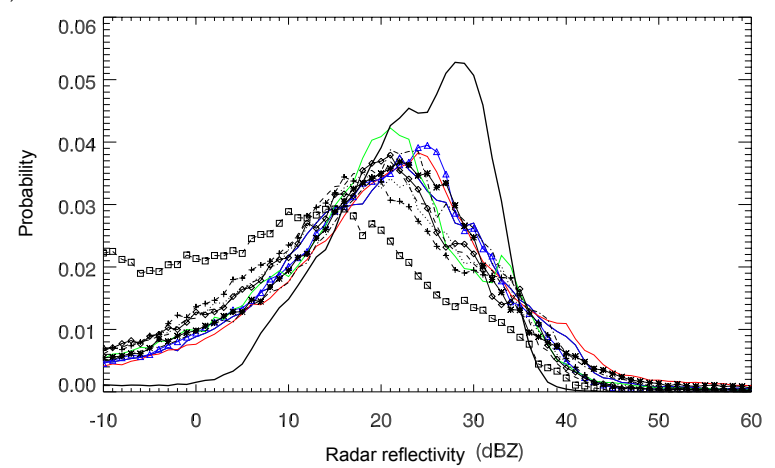

(b)

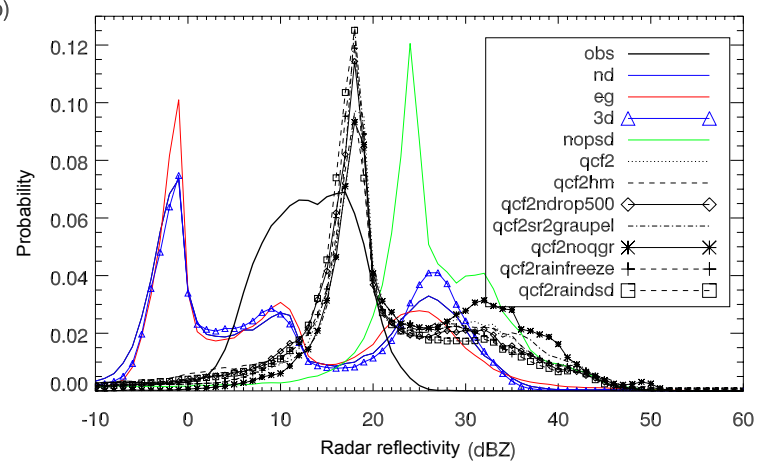

Figure 8. Radar reflectivity probability density functions for two heights, (a) 2.5 and (b) $6 \mathrm{~km}$.

tions except for one use the Abel and Boutle (2012) rain DSD, with the remaining simulation testing the sensitivity of rain drop sizes by using the Marshall and Palmer (1948) DSD. The Abel and Boutle rain DSD represents the observed rain reflectivity distribution fairly well; however, the observed peak of $30 \mathrm{dBZ}$ is underestimated and there are too many occurrences in the tails of the distribution. The contribution from the convective updraughts is demonstrated by the largest occurrences in the high-reflectivity tail coming from the simulation with the different dynamical core (eg). It is this ENDGame simulation that produces the strongest updraughts (Fig. 11) and is the least representative of the observed rain reflectivity distribution for the reflectivities $>40 \mathrm{dBZ}$. The simulation using the Marshall-Palmer DSD (qcf2raindsd) peaks at too low a reflectivity at around $10 \mathrm{dBZ}$ and produces too many small rain drops with low reflectivities.

At $6 \mathrm{~km}$ the observations again show a bimodal reflectivity distribution, with the largest peak centred on approximately $16 \mathrm{dBZ}$ (Fig. 8b). The simulations show a more complicated distribution at this height with multiple modes due to the presence of multiple hydrometeor species. The simulations that use the generic ice PSD parameterisation peak at $-1 \mathrm{dBZ}$ (nd, eg, 3d). When this parameterisation is not used and the explicit ice size distribution is used, the peak is too high at $24 \mathrm{dBZ}$ (nopsd). When an additional ice prog- nostic is added this peak is reduced and compares better to the observations at $18 \mathrm{dBZ}$ (all qcf2 simulations); however, the tail of the distribution in these cases is too long with too many occurrences at high reflectivities. While the tail of the distribution for the generic ice PSD cases is also too long compared to the observed reflectivity distribution, these cases represent the graupel reflectivities better than the cases that use the explicit PSD even though all cases use the same graupel PSD. The better graupel representation with the generic ice PSD coupled with the significantly larger occurrence of weak reflectivities around $0 \mathrm{dBZ}$ is similar to the result found by Lang et al. (2011). They modified microphysics parameterisations to reduce the occurrence of excessive large reflectivities and found that this resulted in too many low reflectivities due to a shift in the reflectivity distribution, as is the case here when comparing the generic and explicit ice PSD cases.

To examine to what extent the generic ice PSD parameterisation is misrepresenting the observed reflectivities or how much the erroneous cloud dynamics are responsible for errors in the modelled reflectivities, the PSD moments derived from the generic PSD parameterisation using the observed IWC and temperature are shown in Fig. 9. In calculating the predicted moments, the observed mass-diameter relation was used, $m=4.97 \times 10^{-3} D^{2.05}$, and the observed moments are calculated only for particle sizes $>100 \mu \mathrm{m}$ in diameter and for IWC $>10^{-3} \mathrm{~g} \mathrm{~m}^{-3}$ to be consistent with the data used to derive the Field et al. (2007) parameterisation. The fourth moment is equivalent to radar reflectivity when mass is proportional to the square of the particle diameter, and it can be seen in Fig. 9a that the parameterised reflectivity results in an overestimate of the larger reflectivities. The generic ice PSD parameterisation underestimates the zeroth and first moments and has a good representation of the third moment. The underestimate of the number concentration (Fig. 9d) is consistent with the overestimation of particle sizes and reflectivities. The observations in this case may be in a different type of cloud environment from the data used to construct the Field parameterisation, as suggested by the observed number concentration being below the lower range shown in Field et al. (2007).

\subsubsection{Maximum reflectivity profiles and vertical velocities}

In agreement with many previous studies (e.g. Blossey et al., 2007; Varble et al., 2011), the model overestimates the reflectivity above the freezing level as can be seen in the profiles of maximum reflectivity shown in Fig. 10, as well as overestimating the rain reflectivities below $5 \mathrm{~km}$. From the set of simulations it can be seen that graupel is not the sole cause of the significantly higher reflectivities, as the simulation without graupel also displays this bias. The largest difference between simulated and observed maximum reflectivity at 23:00-24:00 UTC occurs above $7 \mathrm{~km}$ and increases 
(a)

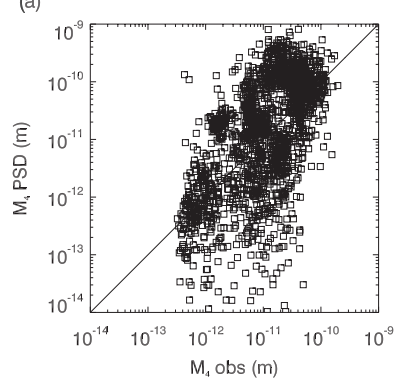

(c)

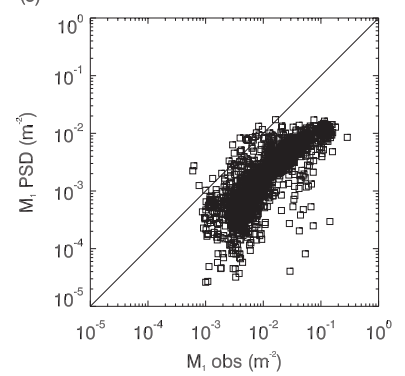

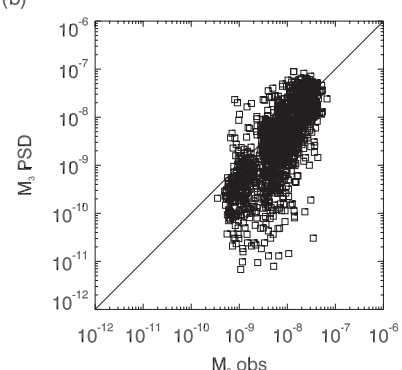

(d)

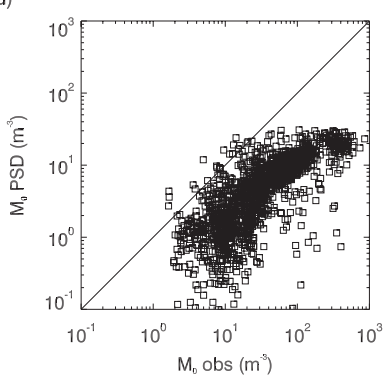

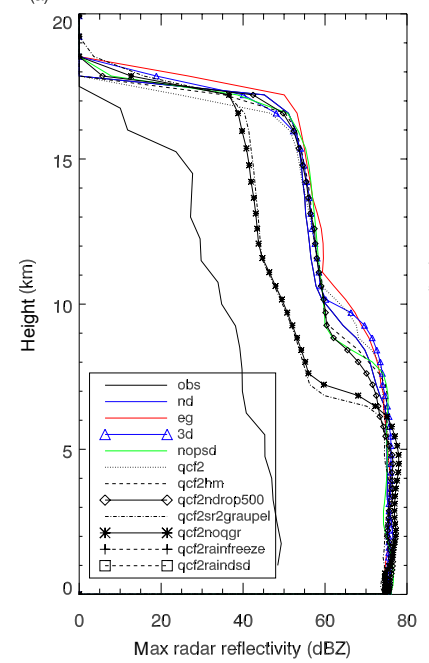

(b)

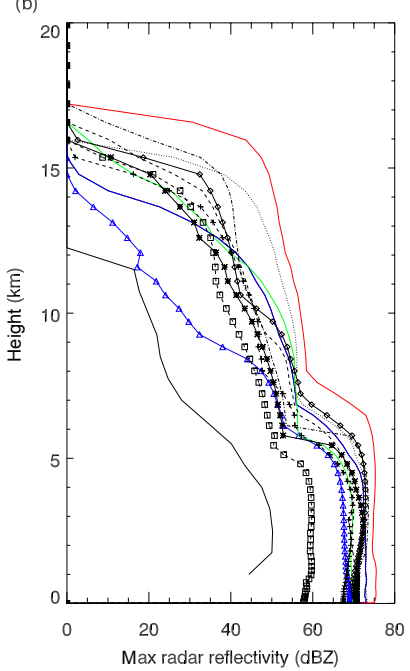

Figure 10. Profiles of maximum radar reflectivity for the times (a) 17:00-18:00 UTC and (b) 23:00-24:00 UTC.

pared to the later less convective times (Fig. 10). The observed $40 \mathrm{dBZ}$ contour reaches $8 \mathrm{~km}$ in agreement with the results of Zipser et al. (2006), who showed that radar echoes of this strength rarely occur above $10 \mathrm{~km}$. The profile of maximum reflectivity from the simulation that uses the new dynamical core (eg) shows essentially the same profile at these strong convective times as for the later times when the MCS has matured, unlike the observations and the majority of the simulations, suggesting that there is less variability in maximum updraught when using ENDGame. There is little spread in the maximum reflectivity profile across the simulations at 17:00-18:00 UTC, with strong updraughts $>20 \mathrm{~m} \mathrm{~s}^{-1}$ in all simulations (not shown) that allow large particles to be advected into the upper troposphere. There is a clear difference between the two simulations that limit or exclude graupel (qcf2noqgr, qcf2sr2graupel), demonstrating that at the time of strongest convection, the vertical advection of graupel is responsible for the largest error in the maximum reflectivities in the upper troposphere.

Comparing the control case with the cases that use a different dynamical core and different turbulent mixing parameterisation (nd, eg, 3d) shows that the reduction in maximum reflectivity with height at 23:00-24:00 UTC is well correlated with the reduction in maximum vertical velocity shown in Fig. 11b. These cases all use the generic ice PSD and the differences are likely due to the different entrainment and water loading that affects the cloud buoyancy and the strength of the updraughts that advect large particles into the upper troposphere. The ENDGame simulation (eg) produces significantly larger maximum updraughts and has less accumulated ice water (see Fig. 13). Conversely there is greater accumulated IWC for the simulation with the different turbulent mixing parameterisation (3d) compared to the control case (nd), 
(a)

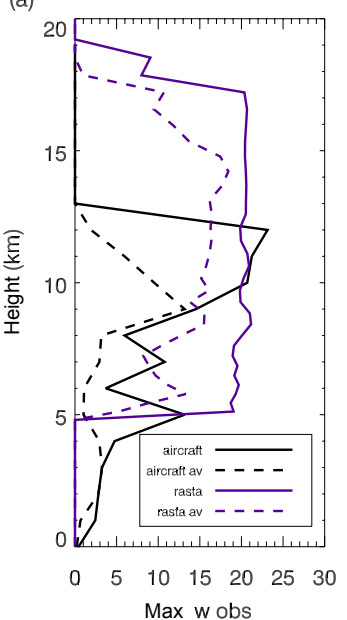

(d)

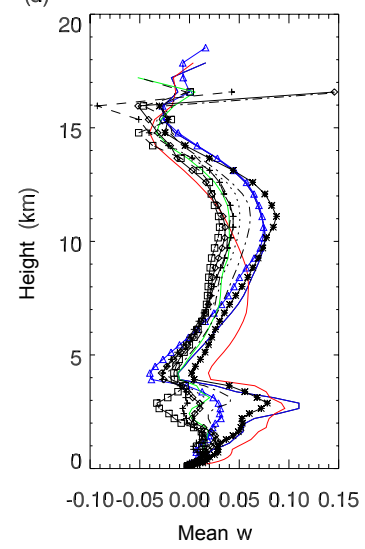

(b)

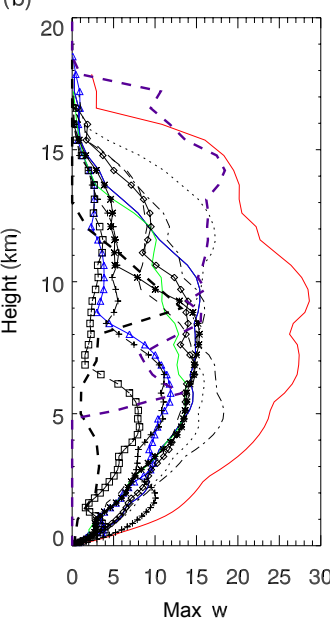

(e)

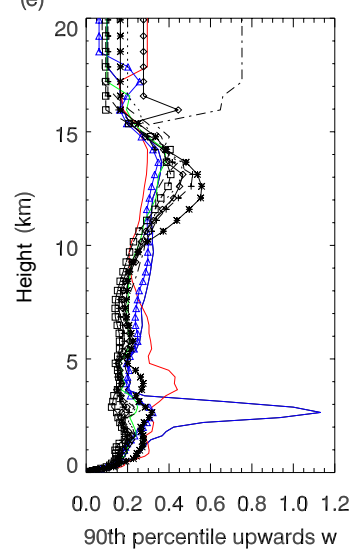

(c)

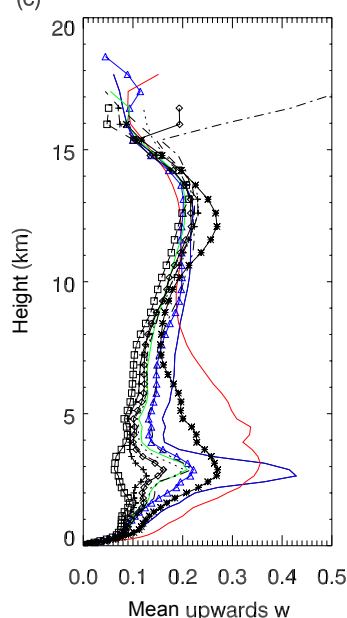

(f)

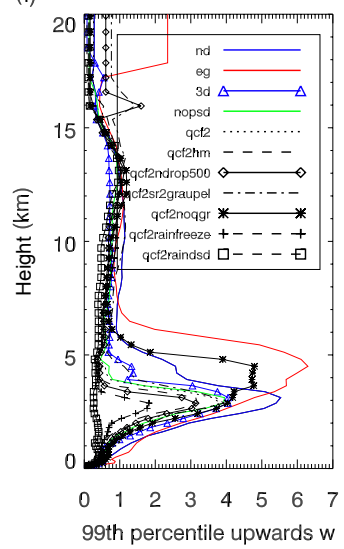

Figure 11. (a) Maximum vertical velocity observed by the aircraft and derived from RASTA (Radar SysTem Airborne) for the times 23:0024:00 UTC. Solid lines use the highest-resolution observations, dashed lines use the observations averaged to the $1 \mathrm{~km}$ resolution. Modelled in-cloud vertical velocity statistics $\left(\mathrm{m} \mathrm{s}^{-1}\right)$ over the radar domain for the times 23:00-24:00 UTC: (b) maximum, (c) updraught mean, (d) mean, (e) updraught 90th percentile and (f) updraught 99th percentile.

supporting the argument that water loading differences likely contribute to the differences in maximum vertical velocities and maximum reflectivities.

Comparing the differences in maximum vertical velocity across the simulations for the times 23:00-24:00 UTC shows that the largest sensitivity tends to come from the choice of dynamics and turbulence (eg, 3d). The reduction in updraught strength at these times with the 3-D Smagorinsky turbulence scheme is also achieved with the inclusion of a heterogeneous freezing rain parameterisation (qcf2rainfreeze). Both of these cases tend to have larger ice water contents in strong updraughts (see Fig. 12), which will reduce buoyancy through the effect of water loading. While there is different sampling between the aircraft observations and the simulations, the aircraft observations of maximum updraught strength shown in Fig. 11 are smaller than the ENDGame simulation (eg) by as much as $20 \mathrm{~m} \mathrm{~s}^{-1}$. In this simulation it seems as though the stronger and deeper updraughts are able to generate enough latent heating that this effect on buoyancy is larger than that of entrainment and water loading compared to the other cases. The in-cloud mean vertical velocity for this simulation is also larger than the other cases from 4 to $8 \mathrm{~km}$, as well as the 99th percentile of upward vertical motion (Fig. 11). The shape of the mean updraught velocity is similar for the ENDGame case and the simulation without graupel (qcf2noqgr), both showing greater mean updraught strength from 3 to $7 \mathrm{~km}$. These two simulations produce the largest domain mean rain rate (Fig. 3a) at these times and show that dynamical changes to the cloud system can be achieved through changes to the model's dynamical core and the cloud microphysics.

While the maximum updraughts produced by the simulations at these times are within the range of observed maximum tropical updraughts from other field campaigns at Darwin (e.g. $<25 \mathrm{~m} \mathrm{~s}^{-1}$ in TWP-ICE; Varble et al., 2014a), the maximum updraughts produced throughout the MCS life 

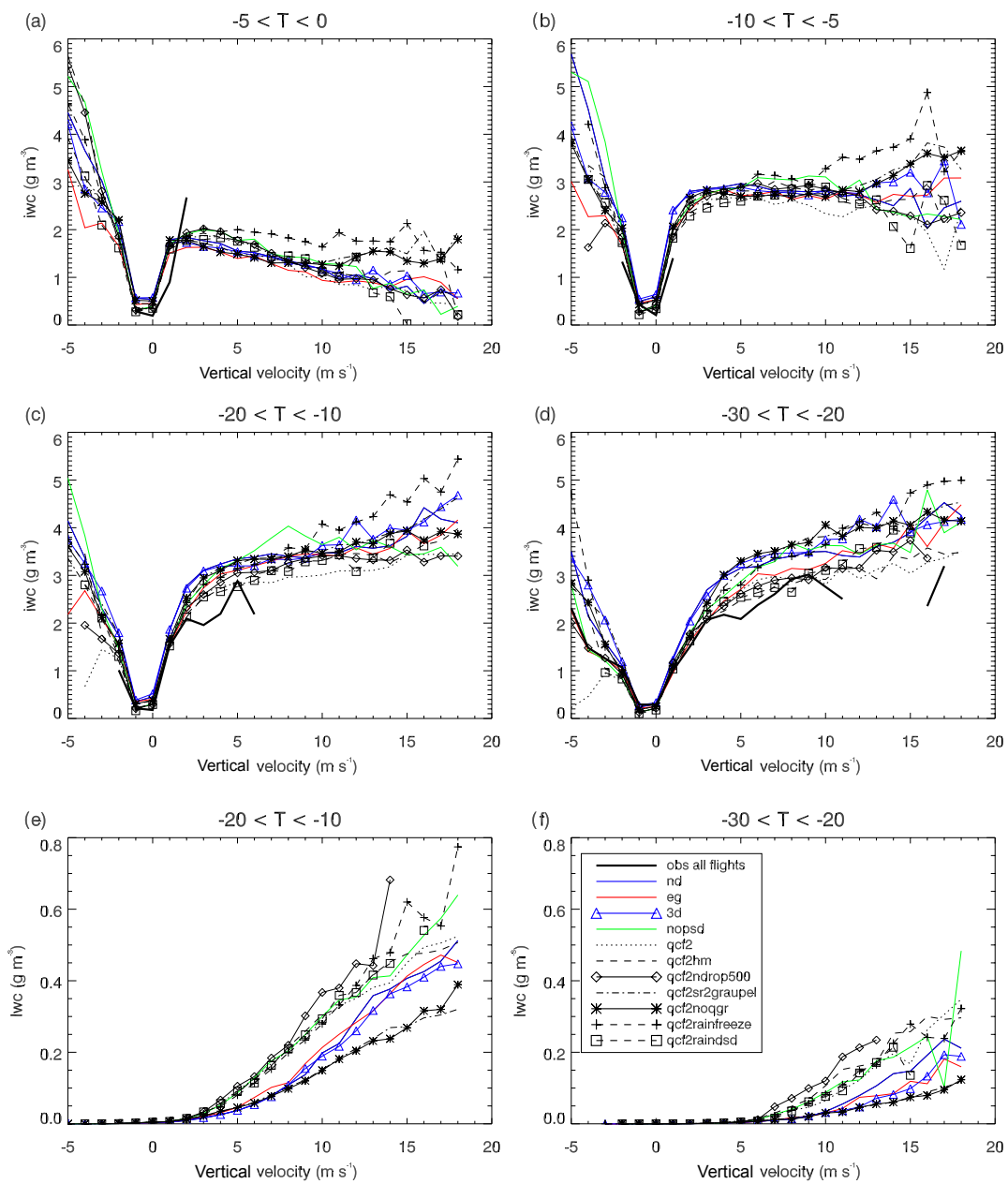

Figure 12. Ice water content $\left(\mathrm{g} \mathrm{m}^{-3}\right)$ as a function of vertical velocity $\left(\mathrm{m} \mathrm{s}^{-1}\right)$ for four temperature regimes: (a) -5 to 0 , (b) -10 to -5 , (c) -20 to -10 and $(\mathbf{d})-30$ to $-20^{\circ} \mathrm{C}$. Panels $(\mathbf{e}, \mathbf{f})$ show liquid water content $\left(\mathrm{g} \mathrm{m}^{-3}\right)$ as a function of vertical velocity for the two coldest regimes: (e) -20 to -10 and (f) -30 to $-20^{\circ} \mathrm{C}$.

cycle are much larger and in excess of $50 \mathrm{~m} \mathrm{~s}^{-1}$ for the ENDGame simulation (eg) at 17:00-18:00 UTC. These values are well outside the range of maximum vertical velocities presented for oceanic convection by Heymsfield et al. (2010) and agree with other studies showing excessive tropical vertical velocities simulated by convection-permitting models. Hanley et al. (2014) demonstrated that the UM with a grid length of $1.5 \mathrm{~km}$ simulated convective cells that were too intense and were initiated too early, as was also shown by Varble et al. (2014a), suggesting that convection is underresolved at grid lengths of order of $1 \mathrm{~km}$. Improved initiation time was shown by Hanley et al. (2014) to occur when the grid length was reduced to 500 and $200 \mathrm{~m}$. However, the intensity of the convective cells was not necessarily improved, with the results being case-dependent. Varble et al. (2014a) showed that in the tropics the intensity of the updraughts remained overestimated even at the $100 \mathrm{~m}$ grid length. Both of these studies suggest that there are missing processes in the model and/or the interactions between convective dynamics and microphysics are incorrectly represented.

Most of the simulations show a double peak in vertical velocities with maxima at $3 \mathrm{~km}$ and in the upper troposphere at about $13 \mathrm{~km}$. The upper-level updraught peak has been observed (e.g. May and Rajopadhyaya, 1999) and is argued to be due to the deep column of convectively available potential energy in the tropics, coupled with latent heat released by freezing condensate and the unloading of hydrometeors, both of which increase parcel buoyancy. A bimodal peak has been observed but tends to be correlated with the freezing level rather than a couple of kilometres lower as in the simulations. The apparent lack of observational support for the low-level peak is likely due to the inability of many observations to distinguish between non-precipitating cloud and clear air, and dual profiler measurements during TWP-ICE do show some evidence of a low-level peak (Collis et al., 2013). 
(a)

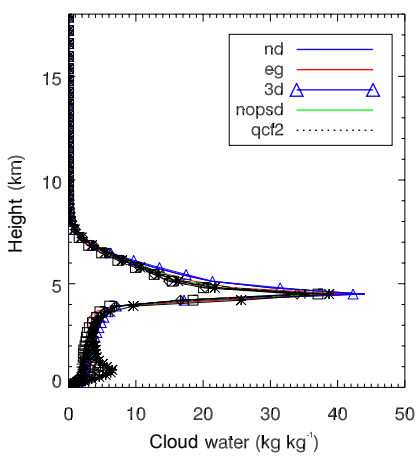

(d)

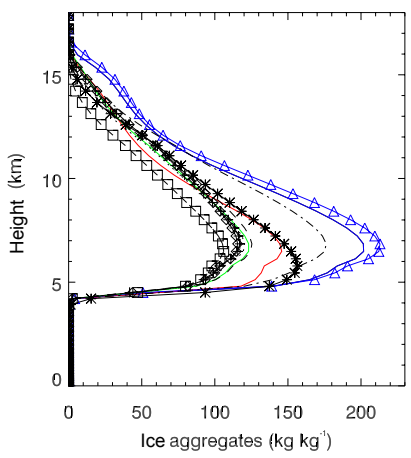

(b)

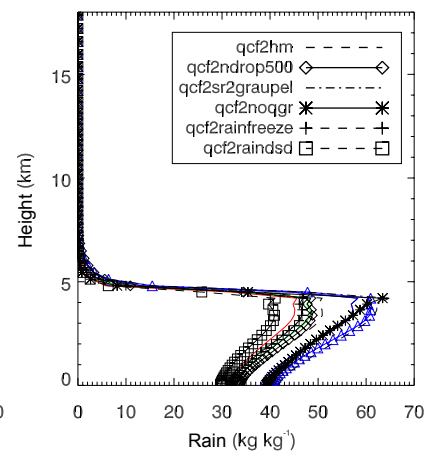

(e)

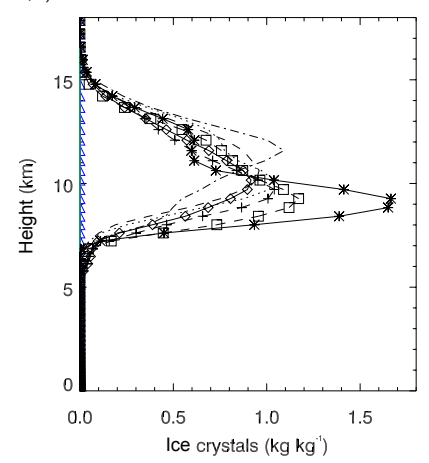

(c)

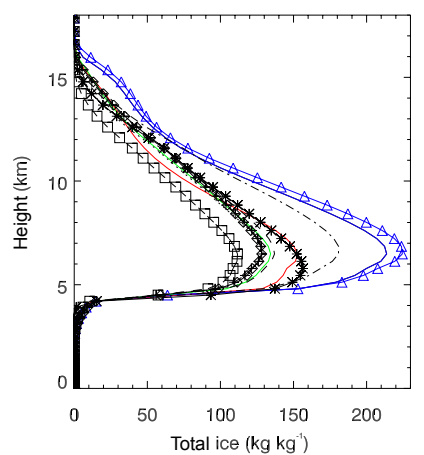

(f)

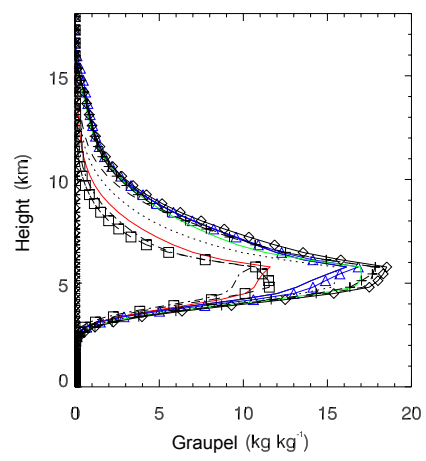

Figure 13. For the aircraft analysis region $\left(150 \mathrm{~km}\right.$ radius from the mean aircraft track), the total accumulated water contents $\left(\mathrm{kg} \mathrm{kg}^{-1}\right)$ over the domain from 23:00 to 24:00 UTC. (a) Cloud liquid water, (b) rain water, (c) total ice, (d) ice aggregates/snow, (e) ice crystals and (f) graupel.

\subsection{Phase composition and comparison with in situ observations}

Due to the small sample size of observations from the single research flight on 18 February 2014, the observations from 18 of the Darwin HIWC flights have been used to allow for a more robust comparison of the model to the observations (Figs. 11, 12 and 14). The majority of the flight time for these cases was in clouds with temperatures $<-10^{\circ} \mathrm{C}$ and vertical motions within the range of -2 to $2 \mathrm{~m} \mathrm{~s}^{-1}$. Therefore, when comparing the model to the aircraft observations, the focus is on this subset of cloud conditions as there are limited observational samples outside of these ranges.

In the simulations, the relationship of IWC to vertical velocity changes with the temperature regime, as shown in Fig. 12. For the warmest range of 0 to $-5^{\circ} \mathrm{C}$ the IWC reduces as the strength of the updraught increases from $1 \mathrm{~m} \mathrm{~s}^{-1}$. For the two intermediate temperature regimes, -5 to -10 and -10 to $-20^{\circ} \mathrm{C}$, the IWC is fairly constant, with vertical velocities greater than $2 \mathrm{~m} \mathrm{~s}^{-1}$ and with the colder regime consisting of $1 \mathrm{~g} \mathrm{~m}^{-3}$ more ice for a given vertical velocity. For the coldest regime analysed the IWC increases as the vertical velocity increases.

For the warmest temperature regime the decline of IWC with updraught speed is offset by the strong increase in LWC, with the fraction of condensate that is supercooled cloud water reaching 0.8 at $15 \mathrm{~m} \mathrm{~s}^{-1}$ (not shown). In this temperature regime there is no new ice being formed as heterogeneous freezing in the model does not occur until the temperature cools to $-10^{\circ} \mathrm{C}$. Any ice in this regime has formed above and has been recirculated into these updraughts and as the vertical velocity increases the saturation-specific humidity increases faster than the supercooled water can be removed by deposition and riming, resulting in the large LWC. The circulation of ice from high levels to those below was suggested by Black and Hallett (1999) to be a factor in the observed rapid glaciation of clouds in hurricanes. The no-graupel and limited-graupel cases (qcf2noqgr, qcf2sr2graupel) do not show the same decline in IWC in the warmest temperature regime. For these cases the fraction of condensate that is supercooled water is lower so there is less competition for the available water vapour, which results in greater depositional ice growth. In these simulations the greater proportion of ice mass with slower fall speeds leads to greater in-cloud residence times, producing larger accumulated IWC than the other cases with two ice prognostics (see Fig. 13). This shows that when graupel is included in the simulations and allowed to grow unrestricted, the removal of LWC by ice processes is less efficient in this tempera- 

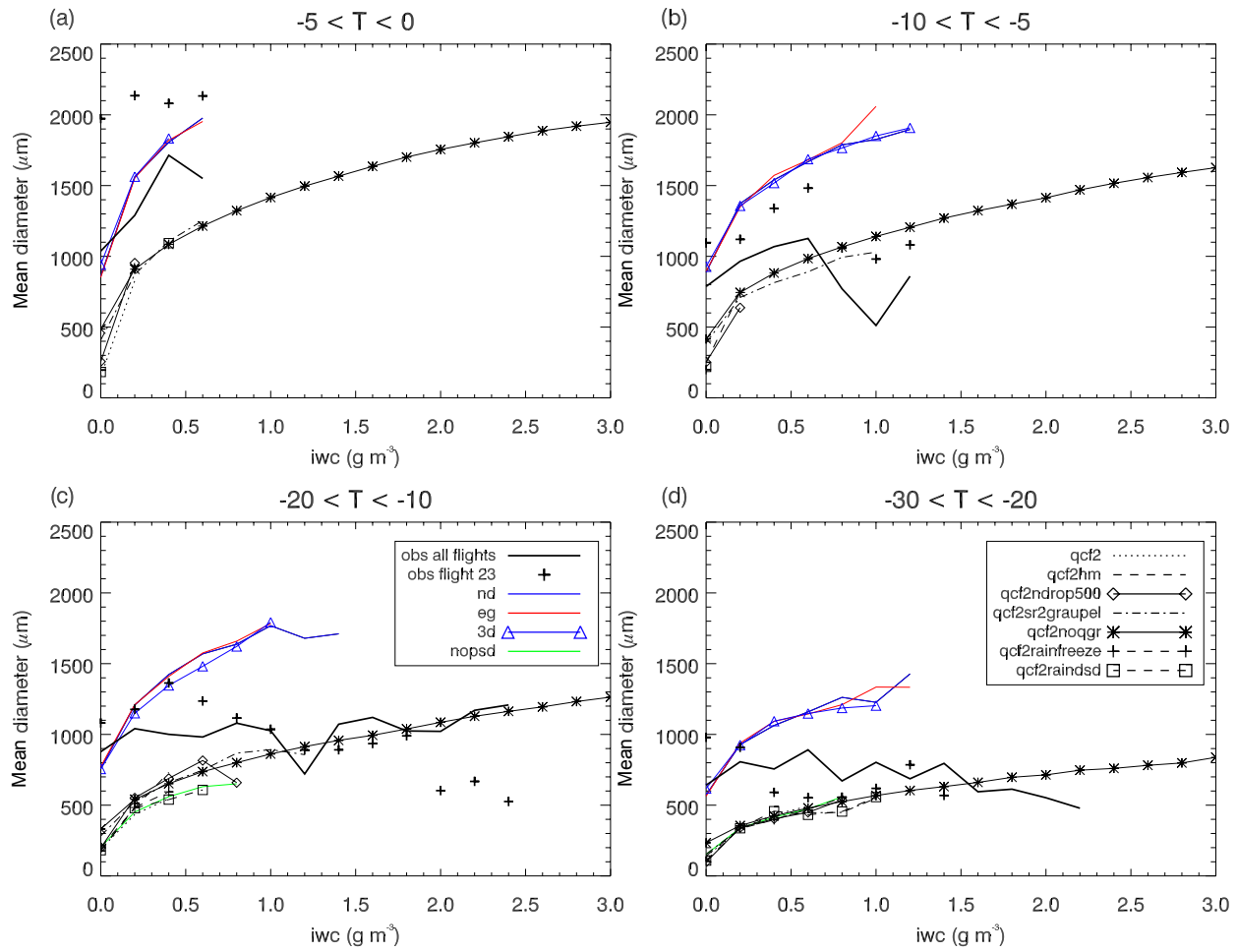

Figure 14. Mean mass-weighted ice particle size $(\mu \mathrm{m})$ as a function of ice water content $\left(\mathrm{g} \mathrm{m}^{-3}\right)$ for four temperature regimes: (a) -5 to 0 , (b) -10 to -5 , (c) -20 to -1 and (d) -30 to $-20^{\circ} \mathrm{C}$.

ture regime. The other simulation with different behaviour and larger IWC in this warmest regime is the case that includes rain heterogeneous freezing (qcf2rainfreeze). In this simulation there is an additional source of ice and this results in greater IWC in strong updraughts due to the rain that is advected upwards, freezing rather than remaining as liquid water as in the other simulations. The impact of this on the cloud liquid water is to increase the cloud water content in strong updraughts as shown in Fig. 12. This is due to the reduction in the riming of cloud water by graupel compared to the accretion of cloud water by rain.

The large IWC in the downdraught regions of the warmer temperature regime is where graupel is expected, which is often located behind and below the convective updraughts (Barnes and Houze, 2014), where the suggestion is that these larger particles help to generate downdraughts through mass loading (Franklin et al., 2005; Jung et al., 2012). This argument is supported by analysis of the downdraught IWC that shows that the majority of the ice in the downdraughts is graupel. For example in the control simulation, $82 \%$ of the ice mass is graupel for the warmest regime downdraught of $5 \mathrm{~m} \mathrm{~s}^{-1}$. The simulated increase in IWC with increasing downdraught speed is observed, with many of the simulations representing the downdraught IWC quantitatively well.

The colder regime of -10 to $-5^{\circ} \mathrm{C}$ shows IWC invariable to vertical velocity. These colder temperatures will produce a greater difference in saturated vapour pressure and saturated vapour pressure over ice, therefore resulting in larger depositional growth rates via the Bergeron-Findeisen process than the warmest temperature regime.

Compared to the warmer temperature regimes, the temperature regime of -20 to $-10^{\circ} \mathrm{C}$ shows a small increase in IWC with vertical velocity (Fig. 12c) due to the effects of heterogeneous freezing (which occurs at temperatures $<-10{ }^{\circ} \mathrm{C}$ ) on increasing the mass of ice and further increases in the vapour pressure. In agreement with the observations, the simulations increase the IWC from 0 to $5 \mathrm{~m} \mathrm{~s}^{-1}$, with the mean modelled IWC increasing from 0.2 to about $3 \mathrm{~g} \mathrm{~m}^{-3}$, which is in good agreement with the observed IWC. For the coldest temperature regime, the modelled relationship of IWC to vertical velocity is represented well for updraught strengths $<9 \mathrm{~m} \mathrm{~s}^{-1}$; however, the modelled IWC tends to be a bit larger, particularly for the simulations that have larger sized snow particles. The spread in IWC across the simulations is typically not statistically significant, particularly for the stronger updraughts; however, the differences can be attributed to the effects that the changes have on producing and removing LWC, with different dynamics, turbulence and microphysics all displaying sensitivities to the amount and distribution of IWC within tropical clouds.

Across the temperature regimes the simulations show an increase in cloud LWC with updraught strength (Fig. 12e, 
f), with the LWC reducing as the temperature cools along with the fraction of condensate that is supercooled liquid water. The strongest updraughts are associated with convective cores that will have minimal entrainment and consequently high supersaturations. The simulations that use the generic ice PSD (nd, eg, 3d) tend to have lower liquid water contents for a given vertical velocity, likely due to the increased accretion and riming growth due to the larger ice particle sizes compared to the explicit PSD (Figs. 4 and 14). Increasing the cloud droplet number concentration in the model (qcf2ndrop500) only directly impacts the microphysical process of autoconversion between cloud droplets and rain, and reduces the precipitation efficiency. For this case the reduced autoconversion rate does not make a significant difference to the surface rainfall, since the ice processes dominate the rainfall production (see Fig. 3). However, the less efficient transfer of cloud water mass to rain does change the cloud structure with more LWC and a larger amount and fraction of condensate being supercooled water for the temperatures between -10 and $-30^{\circ} \mathrm{C}$ (Fig. 12). As cloud water is the only liquid water source used in the model for deposition growth via the Bergeron-Findeisen mechanism and can freeze heterogeneously, this implies potentially greater growth rates for ice.

The other simulation that produces more cloud water for updraughts $>5 \mathrm{~m} \mathrm{~s}^{-1}$ in the coldest temperature regime is the simulation that includes ice splintering or the HallettMossop (H-M) process (qcf2hm; Fig. 12f). Looking at the accumulated ice crystal mass between the simulations that do and do not include an ice splintering parameterisation (Fig. 13, qcf2 and qcf2hm) shows that, while there tends to be less crystal mass at most heights when the $\mathrm{H}-\mathrm{M}$ process is included, there are crystals present in updraughts up to $15 \mathrm{~m} \mathrm{~s}^{-1}$, whereas in the qcf 2 case there are no crystals present in updraughts $>4 \mathrm{~m} \mathrm{~s}^{-1}$ (not shown). Similarly for the aggregates there is ice spread across a wider range of updraughts when the $\mathrm{H}-\mathrm{M}$ process is included, particularly for the colder temperatures, resulting in a larger accumulated amount of snow and total ice (Fig. 13). The generation of a larger quantity of ice crystal mass in the H-M zone allows for a larger amount to be transported to the upper cloud levels by the convective updraughts where the crystals then grow through deposition, riming and aggregation, producing a larger mass of snow.

The observed mean mass-weighted ice diameter from research flight 23 shown in Fig. 14 increases with warmer temperatures and shows a strong dependence on IWC, with the characteristic size decreasing with increasing IWC, reflecting the dominance of smaller particles for higher IWC. This contrasts with the lack of dependence of mean ice particle size on IWC which has been observed in earlier flights over Darwin and Cayenne in 2010-2012 (Fridlind et al., 2015) but agrees with more recent findings by Leroy et al. (2015). By analysing research flights 12,13 and 16, they showed that regions of high IWC over Darwin could be generated in various environments, with the most common result being high concentrations of small crystals, but sometimes smaller concentrations of larger crystals. Figure 14 shows that when using all of the Darwin research flights there is little variability in mean diameter for the temperature range between -10 and $-20^{\circ} \mathrm{C}$, as there were also flights that showed an increase in mean diameter with increasing IWC (Leroy et al., 2015). These findings show similar results to those documented by Gayet et al. (2012), with high concentrations of ice crystals occurring in regions of ice water content $>1 \mathrm{~g} \mathrm{~m}^{-3}$ sustained for at least $100 \mathrm{~s}$ at Darwin (Leroy et al., 2015 ) and $>0.3 \mathrm{~g} \mathrm{~m}^{-3}$ in the overshooting convection in the midlatitudes in western Europe (Gayet et al., 2012). Gayet et al. (2012) proposed that the high concentration of ice crystals, which appeared as chain-like aggregates of frozen drops, could be generated by strong updraughts lofting supercooled droplets that freeze homogeneously. However, using updraught parcel model simulations, Ackerman et al. (2015) showed that this process produced a smaller median mass area equivalent diameter than is observed. They proposed a number of other possible microphysical pathways to explain the observations, including the Hallett-Mossop process and a large source of heterogeneous ice nuclei coupled with the shattering of water droplets when they freeze.

The modelled mean snow diameter increases with increasing temperature, reflecting the process of aggregation; however, the modelled snow PSD also increases the mean diameter with increasing IWC, with the rate of increase being similar in both the generic ice PSD and the explicit specified gamma size distribution. Note that both of the modelled PSDs generally lie within 1 standard deviation of the observations. The mean diameter from the generic ice PSD tends to agree reasonably well with the observed size for IWC $<0.5 \mathrm{~g} \mathrm{~m}^{-3}$; however, the sizes are significantly overestimated for IWC $>0.5 \mathrm{~g} \mathrm{~m}^{-3}$. Given that the number concentration is dependent on the size of the particles for a given IWC, this implies that the generic ice PSD simulates larger concentrations of larger particles than the observations. This reflects the data that were used to develop the generic ice PSD coming largely from stratiform clouds with smaller IWC and larger ice particles. The explicit gamma PSD shows the opposite behaviour, underestimating the mean ice diameter for IWC $<0.5 \mathrm{~g} \mathrm{~m}^{-3}$ and matching the observed size for higher IWC. To more accurately represent the snow sizes in the model for this case a double-moment microphysics scheme is required to be able to better capture the observed variability of the PSD or the use of a wider data set that includes high IWC observations to generate a more applicable generic ice PSD parameterisation for modelling tropical convective cloud systems. 


\section{Conclusions}

A set of $1 \mathrm{~km}$ horizontal grid length simulations has been analysed to evaluate the ability of the UM to simulate tropical convective cloud systems and to investigate the impacts of different dynamical, turbulent and microphysical representations on the cloud properties, including the phase composition. The case study is 18 February 2014, where active monsoon conditions produced a mesoscale convective system in the Darwin area.

Analysing $12 \mathrm{~h}$ of observed and simulated radar reflectivity has shown that the simulations capture the intensification and decay of convective strength associated with the life cycle of the MCS. However, convection occurs too early in the simulations, the radar detectable cloud top heights are overestimated, as are the maximum reflectivities and areas above the freezing level with reflectivities greater than $30 \mathrm{dBZ}$. The observed maximum domain averaged precipitation rate coincides with the generation of significant anvil cloud, whereas the simulations generate the highest mean precipitation rate a few hours too early at the times of deepest convection. Observations of maximum vertical velocity suggest that the new dynamical core simulation (eg) overestimates the strength of convection at the mature-decaying stage of the MCS. In this case the stronger updraughts contribute to the excessive reflectivities above the freezing level, but this was apparent in all of the simulations albeit to a lesser degree, suggesting that both the updraught dynamics and the particle sizes are responsible for this error.

The simulated reflectivity CFADs show more of a convective-type profile compared to the observations, with broader distributions and a greater occurrence of highreflectivity outliers. This suggests a larger number of convective cells in the simulations, as was apparent in the plan views of OLR and $2.5 \mathrm{~km}$ radar reflectivity, which has been seen in tropical convective-scale model intercomparison studies (e.g. Varble et al., 2014a). The simulation with the differing turbulence parameterisation showed the best agreement with the observed maximum reflectivity at the later times of 23:00-24:00 UTC. The change to the 3-D Smagorinsky scheme induces greater mixing, resulting in a reduction of the maximum vertical velocities and reflectivities during the mature decaying MCS stages. This same reduction in the vertical velocity and reflectivity up to $8 \mathrm{~km}$ was also found with a change to the microphysics formulation with the addition of a rain heterogeneous freezing parameterisation. At 17:0018:00 UTC, the time of deepest convection, all simulations showed a similar error in maximum reflectivity regardless of dynamics or turbulence formulation due to the larger and less variable maximum updraughts across all of the simulations at these times.

The largest sensitivities in the maximum updraught velocities are generally produced by changes to the dynamical and turbulence formulations in the model. However, the spread across the simulations for the mean and percentiles of updraught velocity show the greatest sensitivity coming from changes to the microphysical parameters and processes. Changing the microphysics affects the dynamics by altering the vertical distribution of latent heating. The horizontal mass divergence was shown to be most sensitive to the turbulence parameterisation in the mixed-phase regions of the updraughts, where greater mixing generated larger mass divergence, indicative of greater entrainment at these heights. The upper ice-only regions of the convective updraughts showed that the control on updraught buoyancy was the size of the ice particles. Simulations with smaller particles have fewer occurrences of positively buoyancy convective updraughts, reflecting the importance of the microphysical processes on the convective dynamics.

Analysing the relationship between phase composition and vertical velocity for four different temperature regimes showed that the phase composition in the modelled convective updraughts is controlled by the following:

1. the size of the ice particles, with larger particles growing more efficiently through riming, producing larger IWC;

2. the efficiency of the warm rain process, with greater cloud water contents being available to support larger ice growth rates;

3. exclusion or limitation of graupel growth, with more mass contained in slower falling snow particles resulting in an increase of in-cloud residence times and more efficient removal of LWC.

The evaluation of a tropical mesoscale convective system in this study has documented a number of model shortcomings and developments that improve the model performance.

1. Excessive areas with high reflectivities improve with reduced ice sizes, inclusion of a heterogeneous freezing rain parameterisation, an additional ice prognostic variable and increased turbulent mixing through the use of the 3-D Smagorinsky turbulence scheme.

2. Too much rain above the freezing level is reduced with the inclusion of a heterogeneous rain-freezing parameterisation.

3. Too little stratiform cloud and rain area (Fig. 6, Sect. 3.1.1) is increased with increased turbulent mixing.

While the listed model changes do improve aspects of the simulations, none of these produce a simulation that closely matches all of the observations. This study has shown the need to include a better representation of the observed size distribution, which could be achieved through the use of a double-moment microphysics scheme. Being able to predict both the number concentration and mass would allow the model to better represent the observed variability of the PSD, 
which would impact the model's representation of the ice water contents and reflectivities, as well as the convective dynamics through the effects of latent heating and water loading on buoyancy.

\section{Data availability}

Model output and CPOL radar observations are available on request from the first author. With regards to the aircraft observations, please contact Alain Protat (a.protat@bom.gov.au) to discuss data availability.

Acknowledgements. This research has received funding from the Federal Aviation Administration (FAA), Aviation Research Division and Aviation Weather Division, under agreement CON-I-2901 with the Australian Bureau of Meteorology. The research was also conducted as part of the European Union's Seventh Framework Programme in research, technological development and demonstration under grant agreement no. ACP2-GA-2012-314314, and the European Aviation Safety Agency (EASA) Research Programme under service contract no. EASA.2013.FC27. Funding to support the development and testing of the isokinetic bulk TWC probe was provided by the FAA, NASA Aviation Safety Program, Environment Canada and the National Research Council of Canada. Funding for the Darwin flight project was provided by the EU Seventh Framework Programme agreement and EASA contract noted above, the FAA, the NASA Aviation Safety Program, the Boeing Co., Environment Canada and Transport Canada. We acknowledge use of the MONSooN system, a collaborative facility supplied under the Joint Weather and Climate Research Programme, which is a strategic partnership between the Met Office and the Natural Environment Research Council. We would like to express our thanks to Stuart Webster and Adrian Hill for providing the control model configuration, and to Paul Field for suggesting the analysis presented in Fig. 9. The satellite data were provided by the NASA Langley group led by Pat Minnis. The RASTA cloud radar vertical velocity retrieval was generously provided by Julien Delanoë. We thank two anonymous reviewers for comments and suggestions that improved the manuscript.

Edited by: T. Garrett

Reviewed by: two anonymous referees

\section{References}

Abel, S. and Boutle, I. A.: An improved representation of the rain drop size distribution for single-moment microphysics schemes, Q. J. Roy. Meteor. Soc., 138, 2151-2162, 2012.

Abel, S. and Shipway, B. J.: A comparison of cloud-resolving model simulations of trade wind cumulus with aircraft observations taken during RICO, Q. J. Roy. Meteor. Soc., 133, 781-794, 2007.

Ackerman, A. S., Fridlind, A. M., Grandin, A., Dezitter, F., Weber, M., Strapp, J. W., and Korolev, A. V.: High ice water content at low radar reflectivity near deep convection - Part 2: Evaluation of microphysical pathways in updraft parcel simula- tions, Atmos. Chem. Phys., 15, 11729-11751, doi:10.5194/acp15-11729-2015, 2015.

Bange, J., Esposito, M., Lenschow, D. H., Brown, P. R. A., Dreiling, V., Giez, A., Mahrt, L., Malinowski, S. P., Rodi, A. R., Shaw, R. A., Siebert, H., Smit, H., and Zöger, M.: Measurement of Aircraft State and Thermodynamic and Dynamic Variables, in: Airborne Measurements for Environmental Research: Methods and Instruments, edited by: Wendisch, M. and Brenguier, J.-L., Wiley-VCH Verlag GmbH \& Co. KGaA, Weinheim, Germany, doi:10.1002/9783527653218.ch2, 2013.

Barnes, H. C. and Houze Jr., R. A.: Precipitation hydrometeor type relative to mesoscale airflow in mature oceanic deep convection of the Madden-Julian Oscillation, J. Geophys. Res.-Atmos., 119, 13990-14014, doi:10.1002/2014JD022241, 2014.

Baumgardner, D., Jonsson, H., Dawson, W., O'Connor, D. C., and Newton, R: The cloud, aerosol and precipitation spectrometer (CAPS): a new instrument for cloud investigations, Atmos. Res., 59-60, 251-264, 2001.

Bigg, E. K.: The supercooling of water, P. Phys. Soc. Lond. B, 66, 688-694, 1953.

Black, R. and Hallett, J.: Observations of the distribution of ice in hurricanes, J. Atmos. Sci., 43, 802-822, 1999.

Blossey, P. N., Bretherton, C. S., Cetrone, J., and Kharoutdinov, M.: Cloud-resolving model simulations of KWAJEX: Model sensitivities and comparisons with satellite and radar observations, J. Atmos. Sci., 64, 1488-1508, 2007.

Boutle, I. A., Eyre, J. E. J., and Lock, A. P.: Seamless stratocumulus simulation across the turbulent gray zone, Mon. Weather Rev. 142, 1655-1668, 2014.

Cardwell, J. R., Choularton, T. W., Wilson, D., and Kershaw, R.: Use of an explicit model of the microphysics of precipitating stratiform cloud to test a bulk microphysics scheme, Q. J. Roy. Meteorol. Soc., 128, 573-592, 2002.

Clark, A. J., Gallus, W. A., and Chen, T.-C.: Comparison of the diurnal precipitation cycle in convection-resolving and nonconvection-resolving mesoscale models, Mon. Weather Rev., 135, 3456-3473, 2007.

Collis, S., Protat, A., May, P. T., and Williams, C.: Statistics of storm updraft velocities from TWP-ICE including verification with profiling measurements, J. Appl. Meteorol., 52, 1909-1922, 2013.

Cox, G. P.: Modelling precipitation in frontal rainbands, Q. J. Roy. Meteor. Soc., 114, 115-127, 1988.

Davies, T., Cullen, M. J. P., Malcolm, A. J., Mawson, M. H., Staniforth, A., White, A. A., and Wood, N.: A new dynamical core for the Met Office's global and regional modelling of the atmosphere, Q. J. Roy. Meteor. Soc., 131, 1759-1782, 2005.

Davison, C. R., MacLeod, J. D., and Strapp, J. W.: Naturally Aspirating Isokinetic Total Water Content Probe: Evaporator Design and Testing, 1st AIAA Atmospheric and Space Environments, 25 June 2009, San Antonio, Texas, AIAA-2009-3861, 2009.

Del Genio, A. D. and Wu, J.: The role of entrainment in the diurnal cycle of continental convection, J. Climate, 23, 2722-2738, 2010.

Edwards, J. M. and Slingo, A.: Studies with a new flexible radiation code. I: Choosing a configuration for a large-scale model, Q. J. Roy. Meteor. Soc., 122, 689-720, 1996.

Ferrier, B. S.: A double-moment multiple-phase four-class bulk ice scheme. Part I: Description, J. Atmos. Sci., 51, 249-280, 1994. 
Ferrier, B. S., Simpson, J., and Tao, W.-K.: Factors responsible for precipitation efficiencies in midlatitude and tropical squall simulations, Mon. Weather Rev., 124, 2100-2125, 1996.

Field, P. R., Heymsfield, A. J., and Bansemer, A.: Snow size distribution parameterisation for midlatitude and tropical ice clouds, J. Atmos. Sci., 64, 4346-4365, 2007.

Fletcher, N. H.: The Physics of Rain Clouds, Cambridge University Press, 386 pp., 1962.

Franklin, C. N., Holland, G. J., and May, P. T.: Sensitivity of tropical cyclone rainbands to ice-phase microphysics, Mon. Weather Rev., 133, 2473-2493, 2005.

Franklin, C. N., Sun, Z., Bi, D., Dix, M., Yan, H., and BodasSalcedo, A.: Evaluation of clouds in ACCESS using the satellite simulator package COSP: Global, seasonal and regional cloud properties, J. Geophys. Res.-Atmos., 118, 732-748, 2013.

Fridlind, A. M., Ackerman, A. S., Chaboureau, J.-P., Fan, J., Grabowski, W. W., Hill, A. A., Jones, T. R., Khaiyer, M. M., Liu, G., Minnis, P., Morrison, H., Nguyen, L., Park, S., Petch, J. C., Pinty, J.-P., Schumacher, C., Shipway, B. J., Varble, A. C., Wu, X., Xie, S., and Zhang, M.: A comparison of TWP-ICE observational data with cloud-resolving model results, J. Geophys. Res.-Atmos., 117, D05204, doi:10.1029/2011JD016595, 2012.

Fridlind, A. M., Ackerman, A. S., Grandin, A., Dezitter, F., Weber, M., Strapp, J. W., Korolev, A. V., and Williams, C. R.: High ice water content at low radar reflectivity near deep convection - Part 1: Consistency of in situ and remote-sensing observations with stratiform rain column simulations, Atmos. Chem. Phys., 15, 11713-11728, doi:10.5194/acp-15-11713-2015, 2015.

Furtado, K., Field, P. R., Cotton, R., and Baran, A. J.: The sensitivity of simulated high clouds to ice crystal fall speed, shape and size distribution. Q. J. Roy. Meteor. Soc., 141, 1546-1559, doi:10.1002/qj.2457, 2014.

Gayet, J.-F., Mioche, G., Bugliaro, L., Protat, A., Minikin, A., Wirth, M., Dörnbrack, A., Shcherbakov, V., Mayer, B., Garnier, A., and Gourbeyre, C.: On the observation of unusual high concentration of small chain-like aggregate ice crystals and large ice water contents near the top of a deep convective cloud during the CIRCLE-2 experiment, Atmos. Chem. Phys., 12, 727-744, doi:10.5194/acp-12-727-2012, 2012.

Gregory, D. and Rowntree, P. R.: A mass flux convection scheme with representation of cloud ensemble characteristics and stability-dependent closure, Mon. Weather Rev., 118, 14831506, 1990 .

Hallett, J. and Mossop, S. C.: Production of secondary ice particles during the riming process, Nature, 249, 26-28, 1974.

Hanley, K. E., Plant, R. S., Stein, T. H. M., Hogan, R. J., Nicol, J. C., Lean, H. W., Halliwell, C., and Clark, P. A.: Mixing-length controls on high-resolution simulations of convective storms, Q. J. Roy. Meteor. Soc., 141, 272-284, doi:10.1002/qj.2356, 2014.

Heymsfield, A. J., Protat, A., Austin, R. T., Bouniol, D., Delanoë, J., Hogan, R., Okamoto, H., Sato, K., van Zadelhoff, G.-J., Donovan, D., and Wang, Z.: Testing and evaluation of ice water content retrieval methods using radar and ancillary measurements, J. Appl. Meteor. Clim., 47, 135-163, 2008.

Heymsfield, A. J., Bansemer, A., Heymsfield, G., and Fierro, A. O.: Microphysics of maritime tropical convective updrafts at temperatures from $-20^{\circ}$ to $-60^{\circ}$, J. Atmos. Sci., 66, 3530-3562, 2009.

Heymsfield, G. M., Tian, L., Heymsfield, A. J., Li, L., and Guimond, S.: Characteristics of deep tropical and subtropical con- vection from nadir-viewing high-altitude airborne Doppler radar, J. Atmos. Sci., 67, 285-308, 2010.

Hogan, R. J., Mittermaier, M. P., and Illingworth, A. J.: The retrieval of ice water content from radar reflectivity factor and temperature and its use in evaluating a mesoscale model, J. Appl. Meteorol., 45, 301-317, 2006.

Houze, R. A., Hobbs, P. V., Herzegh, P. H., and Parsons, D. B.: Size distributions of precipitation particles in frontal clouds, J. Atmos. Sci., 36, 156-162, 1979.

Jung, S.-A., Lee, D.-I., Jou, B., and Uyeda, H.: Microphysical properties of maritime squall line observed on June 2, 2008 in Taiwan, J. Meteorol. Soc. Jpn., 90, 833-850, 2012.

Keenan, T. D., Glasson, K., Cummings, F., Bird, T. S., Keeler, J., and Lutz, J.: The BMRC/NCAR C-band polarimetric (C-POL) radar system, J. Atmos. Ocean. Tech., 15, 871-886, 1998.

Lang, S. E., Tao, W.-K., Zeng, X., and Li, Y.: Reducing the biases in simulated radar reflectivities from a bulk microphysics scheme: Tropical convective systems, J. Atmos. Sci., 68, 23062320, 2011.

Lawson, R. P., Angus, L. J., and Heymsfield, A. J.: Cloud particle measurements in thunderstorm anvils and possible threat to aviation, J. Aircraft, 35, 113-121, 1998.

Lawson, R. P., O'Connor, D., Zmarzly, P., Weaver, K., Baker, B. A., Mo, Q., and Jonsson, H.: The 2D-S (Stereo) probe: Design and preliminary tests of a new airborne, high speed, high-resolution particle imaging probe, J. Atmos. Ocean. Tech., 23, 1462-1477, 2006.

Leroy, D., Fontaine, E., Schwarzenboeck, A., Strapp, J. W., Lilie, L., Delanoë, J., Protat, A., Dezitter, F., and Grandin, A.: HAIC/HIWC field campaign-specific findings on PSD microphysics in high IWC regions from in situ measurements: Median mass diameters, particle size distribution characteristics and ice crystal shapes, Tech. Rep. 2015-01-2087, SAE International, Warrendale, PA, USA, doi:10.4271/2015-01-2087, 2015.

Liu, G. and Curry, J.: Remote sensing of ice water characteristics in tropical clouds using aircraft microwave measurements, J. Appl. Meteor., 37, 337-355, 1999.

Lock, A. P., Brown, A. R., Bush, M. R., Martin, G. M., and Smith, R. N. B.: A new boundary-layer mixing scheme. Part I: Scheme description and single-column model tests, Mon. Weather Rev., 128, 3187-3199, 2000.

Marshall, J. S. and Palmer, W. M. K.: The distribution of raindrops with size, J. Meteoro., 5, 165-166, 1948.

Mason, J. G., Strapp, J. W., and Chow, P.: The ice particle threat to engines in flight, 44th AIAA Aerospace Sciences Meeting, Reno, Nevada, 9-12 January 2006, AIAA-2006-206, available at: http: //arc.aiaa.org/doi/abs/10.2514/6.2006-206 (last access: 15 July 2016), 2006.

May, P. T. and Lane, T.: A method for using weather radar data to test cloud resolving models, Meteorol. Appl., 16, 425-432, 2009.

May, P. T. and Rajopadhyaya, D. K.: Vertical velocity characteristics of deep convection over Darwin, Australia, Mon. Weather Rev., 127, 1056-1071, 1999.

McBeath, K., Field, P. R., and Cotton, R. J.: Using operational weather radar to assess high-resolution numerical weather prediction over the British Isles for a cold air outbreak, Q. J. Roy. Meteor. Soc., 140, 225-239, 2014. 
Minnis, P. and Smith Jr., W. L.: Cloud and radiative fields derivedfrom GOES-8 during SUCCESS and the ARM-UAV spring 1996 flight series, Geophys. Res. Lett., 25, 1113-1116, 1998.

Minnis, P., Trepte, Q. Z., Sun-Mack, S., Chen, Y., Doelling, D. R., Young, D. F., Spangenberg, D. A., Miller, W. F., Wielicki, B. A., Brown, R. R., Gibson, S. C., and Geier, E. B.: Cloud detection in non-polar regions for CERES using TRMM VIRS and Terra and Aqua MODIS data, IEEE T. Geosci. Remote Sens., 46, 38573884, 2008.

Minnis, P., Sun-Mack, S., Young, D. F., Heck, P. W., Garber, D. P., Chen, Y., Spangenberg, D. A., Arduini, R. F., Trepte, Q. Z., Smith, W. L., Ayers, J. K., Gibson, S. C., Miller, W. F., Chakrapani, V., Takano, Y., Liou, K.-N., Xie, Y., and Yang, P.: CERES Edition 2 cloud property retrievals using TRMM VIRS and Terra and Aqua MODIS data - Part I: Algorithms, IEEE T. Geosci. Remote Sens., 11, 4374-4400, doi:10.1109/TGRS.2011.2144601, 2011.

Mitchell, D. L.: Use of mass- and are-dimensional power laws for determining precipitation particle terminal velocities, J. Atmos. Sci., 53, 1710-1722, 1996.

Morrison, H., Thompson, G., and Tatarskii, V.: Impact of cloud microphysics on the development of trailing stratiform precipitation in a simulated squall line: Comparison of one- and two-moment schemes, Mon. Weather Rev., 137, 991-1007, 2009.

Protat, A. and Williams, C. R.: The Accuracy of Radar Estimates of Ice Terminal Fall Speed from Vertically Pointing Doppler Radar Measurements, J. Appl. Meteorol. Clim., 50, 2120-2138, 2011.

Protat, A. and Zawadzki, I.: A Variational Method for RealTime Retrieval of Three-Dimensional Wind Field from MultipleDoppler Bistatic Radar Network Data, J. Atmos. Ocean. Tech., 16, 432-449, 1999.

Puri, K., Dietachmayer, G., Steinle, P., Dix, M., Rikus, L., Logan, L., Naughton, M., Tingwell, C., Xiao, Y., Barras, V., Bermous, I., Bowen, R., Deschamps, L., Franklin, C., Fraser, J., Glowacki, T., Harris, B., Lee, J., Le, T., Roff, G., Sulaiman, A., Sims, H., Sun, X., Sun, Z., Zhu, H., Chattopadhyay, M., and Engel, C.: Implementation of the initial ACCESS numerical weather prediction system, Aust. Meteorol. Oceanogr. J., 63, 265-284, 2013.

Shige, S., Takayabu Y. N., Kida, S., Tao, W.-K., Zeng, X., Yokoyama, C., and L'Ecuyer, T.: Spectral retrieval of latent heating profiles from TRMM PR data. Part IV: Comparison of lookup tables from two- and there-dimensional cloud-resolving model simulations, J. Climate, 22, 5577-5594, 2009.

Smagorinsky, J.: General circulation experiments with the primitive equations. I: The basic experiment, Mon. Weather Rev., 91, 99164, 1963.

Smith, R. N. B.: A scheme for predicting layer clouds and their water contents in a general circulation model, Q. J. Roy. Meteor. Soc., 116, 435-460, 1990.

Stith, J. L., Dye, J. E., Bansemer, A., and Heymsfield, A. J.: Microphysical observations of tropical clouds, J. Appl. Meteorol., 41, 97-117, 2002.

Stith, J. L., Hagerty, A., Heymsfield, A. J., and Grainger, C. A.: Microphysical characteristics of tropical updrafts in clean conditions, J. Appl. Meteorol., 43, 779-794, 2004.

Strapp, J. W., Isaac, G. A., Korolev, A., Ratvasky, T., Potts, R., May, P., Protat, A., Minnis, P., Ackerman, A., Fridlind, A., Haggerty, J., and Riley, J.: The High Ice Water Content (HIWC) Study of deep convective clouds: Science and technical plan, FAA Rep. DOT/FAA/TC-14/31, in press, 2015.

Tao, W.-K., Sui, C.-H., Ferrier, B., Lang, S., Scala, J., Chou, M.D., and Pickering, K.: Heating, moisture and water budgets of tropical and midlatitude squall lines. Comparisons and sensitivity to longwave radiation, J. Atmos. Sci., 50, 673-690, 1993.

VanWeverberg, K., Vogelmann, A. M., Lin, W., Luke, E. P., Cialella, A., Minnis, P., Khaiyer, M., Boer, E. R., and Jensen, M. P.: The role of cloud microphysics parameterisation in the simulation of mesoscale convective system clouds and precipitation in the Tropical Western Pacific, J. Atmos. Sci., 70, 1104-1181, 2013.

Varble, A., Fridlind, A. M., Zipser, E. J., Ackerman, A. S., Chaboureau, J.-P., Fan, J., Hill, A., McFarlane, S. A., Pinty, J.P., and Shipway, B.: Evaluation of cloud-resolving model intercomparison simulations using TWP-ICE observations: Precipitation and cloud structure, J. Geophys. Res.-Atmos., 116, D12206, doi:10.1029/2010JD015180, 2011.

Varble, A., Zipser, E. J., Fridlind, A. M., Zhu, P., Ackerman, A. S., Chaboureau, J.-P., Collis, S., Fan, J., Hill, A., and Shipway, B.: Evaluation of cloud-resolving and limited area model intercomparison simulations using TWP-ICE observations. Part I: Deep convective updraft properties, J. Geophys. Res.-Atmos., 119, 13891-13918, 2014a.

Varble, A., Zipser, E. J., Fridlind, A. M., Zhu, P., Ackerman, A. S., Chaboureau, J.-P., Fan, J., Hill, A., Shipway, B., and Williams, C.: Evaluation of cloud-resolving and limited area model intercomparison simulations using TWP-ICE observations. Part 2: Precipitation microphysics. J. Geophys. Res.-Atmos., 119, 13919-13945, doi:10.1002/2013JD021372, 2014b.

Waliser, D. E., Li, J.-L. F., Woods, C. P., Austin, R. T., Bacmeister, J., Chern, J., Del Genio, A., Jiang, J. H., Kuang, Z., Meng, H., Minnis, P., Platnick, S., Rossow, W. B., Stephens, G. L., SunMack, S., Tao, W.-K., Tompkins, A. M., Vane, D. G., Walker, C., and Wu, D.: Cloud ice: A climate model challenge with signs and expectations of progress, J. Geophys. Res., 114, D00A21, doi:10.1029/2008JD010015, 2009.

Walters, D. N., Brooks, M. E., Boutle, I. A., Melvin, T. R. O., Stratton, R. A., Bushell, A. C., Copsey, D., Earnshaw, P. E., Gross, M. S., Hardiman, S. C., Harris, C. M., Heming, J. T., Klingaman, N. P., Levine, R. C., Manners, J., Martin, G. M., Milton, S. F., Mittermaier, M. P., Morcrette, C. J., Riddick, T. C., Roberts, M. J., Selwood, P. M., Tennant,W.J., Vidale, P.-L.,Wilkinson, J. M., Wood, N., Woolnough, S. J., and Xavier, P. K.: The Met Office Unified Model Global Atmosphere 6.0 and JULES Global Land 6.0 configurations, in preparation, 2015.

Weusthoff, T., Ament, F., Arpagaus, M., and Rotach, M. W.: Assessing the benefits of convection-permitting models by neighbourhood verification: Examples from MAP D-PHASE, Mon. Weather Rev., 138, 3418-3433, 2010.

Wilkinson, J. M.: The Large-Scale Precipitation Parameterisation Scheme, Unified Model Documentation Paper 26, Met Office, Exeter, UK, available at: http://collab.metoffice.gov.uk/ twiki/pub/Support/Umdp/026_84.pdf (last access: 15 July 2016), 2013.

Wilson, D. R. and Ballard, S. P.: A microphysically based precipitation scheme for the UK Meteorological Office Unified Model, Q. J. Roy. Meteor. Soc., 125, 1607-1636, 1999.

Wilson, D. R., Bushell, A. C., Kerr-Munslow, A. M., Jeremy, D. P., and Morcrette, C. J.: PC2: A prognostic cloud fraction and 
condensation scheme. I: Scheme description, Q. J. Roy. Meteor. Soc., 134, 2093-2107, 2008.

Wisner, C., Orville, H. D., and Myers, C.: A numerical model of a hail bearing cloud, J. Atmos. Sci., 29, 1160-1181, 1972.

Wood, N., Staniforth, A., White, A., Allen, T., Diamantakis, M., Gross, M., Melvin, T., Smith, C., Vosper, S., Zerroukat, M., and Thuburn, J.: An inherently mass-conserving semi-implicit semiLagrangian discretization of the deep-atmosphere global nonhydrostatic equations, Q. J. Roy. Meteor. Soc., 140, 1505-1520, doi:10.1002/qj.2235, 2014.
Yuter, S. E. and Houze Jr., R. A.: Three-dimensional kinematic and microphysical evolution of Florida cumulonimbus. Part III: Vertical mass transport, mass divergence, and synthesis, Mon. Weather Rev., 123, 1964-1983, 1995.

Zipser, E. J., Cecil, D. J., Liu, C., Nesbitt, S. W., and Yorty, D. P.: Where are the most intense thunderstorms on Earth?, B. Am. Meteorol. Soc., 87, 1057-1071, 2006. 